\title{
Kinetic energy analysis of the response of the Atlantic meridional overturning circulation to $\mathrm{CO}_{2}$-forced climate change
}

\author{
J. M. Gregory $\cdot$ R. Tailleux
}

Received: 18 February 2010/Accepted: 13 May 2010/Published online: 6 June 2010

(c) The Author(s) 2010. This article is published with open access at Springerlink.com

\begin{abstract}
Atmosphere-ocean general circulation models (AOGCMs) predict a weakening of the Atlantic meridional overturning circulation (AMOC) in response to anthropogenic forcing of climate, but there is a large model uncertainty in the magnitude of the predicted change. The weakening of the AMOC is generally understood to be the result of increased buoyancy input to the north Atlantic in a warmer climate, leading to reduced convection and deep water formation. Consistent with this idea, model analyses have shown empirical relationships between the AMOC and the meridional density gradient, but this link is not direct because the large-scale ocean circulation is essentially geostrophic, making currents and pressure gradients orthogonal. Analysis of the budget of kinetic energy (KE) instead of momentum has the advantage of excluding the dominant geostrophic balance. Diagnosis of the KE balance of the HadCM3 AOGCM and its low-resolution version FAMOUS shows that KE is supplied to the ocean by the wind and dissipated by viscous forces in the global mean of the steady-state control climate, and the circulation does work against the pressure-gradient force, mainly in the Southern Ocean. In the Atlantic Ocean, however, the pressure-gradient force does work on the circulation,
\end{abstract}

J. M. Gregory ( $\square)$

Climate Division, National Centre for Atmospheric Science,

Meteorology Building, University of Reading,

P O Box 243, RG6 6BB Reading, UK

e-mail: j.m.gregory@ reading.ac.uk

J. M. Gregory

Met Office Hadley Centre, Exeter, UK

R. Tailleux

Department of Meteorology, University of Reading,

Reading, UK especially in the high-latitude regions of deep water formation. During $\mathrm{CO}_{2}$-forced climate change, we demonstrate a very good temporal correlation between the AMOC strength and the rate of KE generation by the pressuregradient force in $50-70^{\circ} \mathrm{N}$ of the Atlantic Ocean in each of nine contemporary AOGCMs, supporting a buoyancy-driven interpretation of AMOC changes. To account for this, we describe a conceptual model, which offers an explanation of why AOGCMs with stronger overturning in the control climate tend to have a larger weakening under $\mathrm{CO}_{2}$ increase.

Keywords Atlantic meridional overturning circulation . Ocean kinetic energy $\cdot$ Climate change

\section{Introduction}

Contemporary atmosphere-ocean general circulation models (AOGCMs) give a range of projections for change in the Atlantic meridional overturning circulation (AMOC) during the twenty-first century. For instance, under scenario SRES A1B for anthropogenic emissions of greenhouse gases and sulphate aerosols (Nakićenović et al. 2000), the AOGCMs of the Coupled Model Intercomparison Project Phase 3 (CMIP3) show reductions of between 0 and $50 \%$ by the end of the century (Schmittner et al. 2005; Meehl et al. 2007, their Fig 10.15). The projected decline in the circulation is gradual, and none of the models indicates a rapid and complete collapse, which would produce a strong cooling in the north Atlantic (e.g. Vellinga and Wood 2002), owing to the cessation of the northward heat transport by the AMOC. Nonetheless, the projected weakening of the AMOC would have a significant climatic effect, offsetting some of the greenhouse warming in 
affected regions, especially Europe (Gregory et al. 2005; Meehl et al. 2007; Vellinga and Wood, 2007). Reducing the large uncertainty in the projected AMOC weakening is therefore of practical importance as well as theoretical interest (Kuhlbrodt et al. 2009).

The southward flow of cold North Atlantic Deep Water constitutes the lower path of the overturning circulation, whose upper path is the northward flow of warm water in the western boundary current and North Atlantic Drift. Weakening of the AMOC under scenarios of global warming is generally understood to be due to increasing surface buoyancy flux into the Atlantic Ocean, especially at high latitudes, leading to reduced convection and deep water formation there. Reduced heat loss from the highlatitude ocean implies a positive change in the buoyancy flux into the ocean. Increasing freshwater input from greater runoff and precipitation also contributes to an increasing buoyancy flux. Gregory et al. (2005) compared the change in $\mathrm{AMOC}$ in various models under a standard idealised scenario in which $\mathrm{CO}_{2}$ increases at $1 \%$ per year compounded, finding that in all of them the AMOC was more strongly influenced by the change in surface heat flux than by the change in surface freshwater flux. Sea-ice retreat could affect both heat and freshwater fluxes and thus have a large influence on the weakening of the AMOC (Saenko et al. 2004; Levermann et al. 2007; Weaver et al. 2007).

In some earlier AOGCMs, changes in the freshwater flux dominated in $\mathrm{CO}_{2}$-forced climate change (Dixon and Lanzante 1999), and many model studies have investigated the effect of freshwater forcing on the Atlantic (e.g. Stouffer et al. 2006; Saenko et al. 2007; Swingedouw et al. 2007; Smith and Gregory 2009; Kleinen et al. 2009), motivated partly because ice-sheet meltwater runoff and discharge have been implicated in causing large and rapid concomitant changes in the AMOC and in regional climate inferred from proxy evidence during glacial periods and deglaciation. There is a possibility of future AMOC changes caused by ablation of the Greenland ice sheet under a warming climate. However, such effects are not included in most AOGCMs, which lack detailed representations of ice-sheet surface mass balance or dynamics; they are therefore not responsible for the spread of AMOC projections for the twenty-first century.

The influence of surface buoyancy fluxes on the AMOC operates via their effect on ocean interior density. Weaver (1994) and Rahmstorf (1996) demonstrated relationships between the meridional density gradient and the AMOC strength in various steady (or quasi-steady) states of their models. Thorpe et al. (2001) showed a similar relationship during time-dependent climate change in $\mathrm{CO}_{2}$-forced simulations with the HadCM3 AOGCM. They considered the meridional gradient of the depth-integrated anomaly of density with respect to the control, $\mathrm{d} / \mathrm{d} \lambda \int_{\mathrm{Z}}^{0} \Delta \rho \mathrm{d} z$, where $\lambda$ is latitude. The integral over the vertical coordinate was taken between the surface $z=0$ and a reference level $z=Z=-3,000 \mathrm{~m}$, thus including both the upper (northward, above about $1,000 \mathrm{~m}$ depth) and lower (southward) branches of the AMOC. (This quantity was expressed as "steric height gradient" by dividing it by a reference density.) In $\mathrm{CO}_{2}$-forced simulations with the IPSL-CM4 AOGCM, Swingedouw et al. (2007) showed a relationship between time-dependent changes in the AMOC strength and the density anomaly in the regions of deep convection in the north Atlantic (north of $45^{\circ} \mathrm{N}$, approximately) integrated over the whole ocean depth.

All these results are consistent with the notion that the meridional density gradient produces a pressure gradient that drives the overturning circulation, as demonstrated by Griesel and Maqueda (2006). This idea is of course the basis of the two-box model of Stommel (1961), in which the flow "is directed from the high pressure (high density) vessel towards the low pressure (low density) vessel by a simple linear law", wherein the flow depends on the density difference. However in the three-dimensional ocean the meridional overturning circulation is not simply related to the meridional pressure gradient in this manner, since the ocean is geostrophic on large scales, and meridional flow relates to zonal pressure gradients. Therefore in the two-dimensional (zonally averaged, depth-latitude) ocean model of Wright and Stocker (1991), Stocker et al. (1992) and Petoukhov et al. (2000), a parametrisation was used to relate the zonal and meridional pressure gradients, based on results from the ocean GCM of Weaver and Sarachik (1990). This parametrisation and the relationships found in GCMs between meridional overturning circulation and density gradients are all empirical results. They describe, but do not explain, the dynamical relationship between the ocean interior density and the AMOC.

An alternative approach to the dynamical force-balance idea is to consider the energetics of the circulation (Oort et al. 1989; Toggweiler and Samuels 1998; Tailleux 2009). Kinetic energy (KE) is supplied to the ocean by the surface windstress and dissipated by internal friction (viscosity) and boundary friction. The pressure-gradient force can be either a source or a sink of KE; potential energy created by buoyancy forcing is converted into KE via this term. The interpretation of these terms as driving forces or brakes is obvious; it depends on whether they increase or reduce KE. On the other hand, the KE balance does not tell us the velocity field; the KE balance is diagnostic of the circulation, the force balance prognostic. Nonetheless an energetic analysis offers the possibility of accounting for the differences in AMOC changes among AOGCMs by analysing changes in the sources and sinks of KE. That is the purpose of the present paper. We use the CMIP3 database 
to investigate the response of the AMOC to greenhouse forcing. However, the range of diagnostics from CMIP3 is limited. We therefore begin with a more detailed analysis of the HadCM3 AOGCM and its low-resolution version FAMOUS, in which we have implemented additional diagnostics for analysis of the dynamics and energetics of the circulation.

The HadCM3 AOGCM (Gordon et al. 2000) has an ocean model with a horizontal resolution of $1.25^{\circ}$ and 20 vertical levels. This model has been used over the last decade in a very wide range of studies of climate variability and change. The FAMOUS AOGCM (Jones et al. 2005 ) has the same ocean levels, but a horizontal resolution of $3.75^{\circ}$ longitude and $2.5^{\circ}$ latitude. It also uses a lower atmospheric resolution than HadCM3 and longer timesteps in both submodels, with the result that it runs about 10 times faster, making practical some investigations where HadCM3 would take too much CPU time. In the present work, FAMOUS was valuable for developing diagnostic techniques, as it is almost identical in formulation to HadCM3. We use FAMOUS version xbyvs (Smith et al. 2008, http://www.famous.ac.uk).

\section{Momentum balance in the global ocean}

In HadCM3, FAMOUS, and many other AOGCMs that likewise follow the Boussinesq and hydrostatic approximations, the equation of motion (the momentum balance) of the ocean takes the form

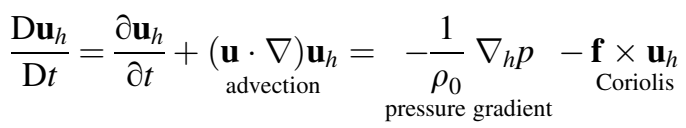

$$
\begin{aligned}
& +\underset{\text { vertical diffusion }}{\frac{1}{\rho_{0}} \mathbf{F}_{v}}+\underset{\text { horizontal diffusion }}{\frac{1}{\rho_{0}} \mathbf{F}_{h}}
\end{aligned}
$$

where $\mathbf{u}$ is velocity, the " $h$ " subscript indicates the horizontal component, $t$ is time, $p$ pressure, $\rho_{0}$ the Boussinesq reference density, $\mathbf{f}$ the product of the Coriolis parameter and the vertical unit vector and $\mathbf{F}_{v, h}$ the convergence of horizontal momentum due to vertical and horizontal mixing processes, which in HadCM3 and FAMOUS are parametrised as diffusive, with a stability- and depthdependent vertical viscosity and a latitude-dependent horizontal viscosity. We have programmed separate diagnostics in our models for each of the terms named in Eq. 1.

In this analysis, we are concerned with time-means over years. On such timescales, the tendency term $\partial \mathbf{u}_{h} / \partial t$ is unimportant compared with the dominant forces (an energetic estimate below confirms this); that is, the forces, while variable, are always nearly in balance. The dominant force terms are the pressure gradient, Coriolis and vertical diffusion. The latter is important because it includes the surface input of momentum by the wind.

The area-mean magnitudes of the accelerations due to the various forces are shown in Fig. 1 as a function of depth in the Atlantic Ocean for a 140-year mean of the HadCM3 control climate e.g. $1 / A(z) \int\left|\nabla_{h} p\right| / \rho_{0} \mathrm{~d} A$ for the pressure-gradient term, where the integral is over the area $A(z)$ of the ocean at level $z$. All the terms decline with increasing depth. Advection and horizontal diffusion are two orders of magnitude smaller than the dominant terms at any depth. At depths greater than a few tens of metres, the pressure-gradient and Coriolis terms are equal in magnitude and all others are negligible, i.e. the ocean is geostrophic. Near the surface, within the Ekman layer, vertical transport of horizontal momentum is also significant, and perturbs the geostrophic balance. In HadCM3 and FAMOUS, there is no bottom friction, so $\int_{-H}^{0} \mathbf{F}_{v} \mathrm{~d} z=\tau$, the surface windstress, where $H$ is the depth of the sea-floor.

Figure 1 also shows the vertical profile of northward volume transport $\iint_{z}^{0} v \mathrm{~d} z^{\prime} \mathrm{d} \phi$, where $v$ is the meridional component of $\mathbf{u}_{h}$, integrated over all longitude $\phi$ across the Atlantic at $35^{\circ} \mathrm{N}$, which is the latitude of the maximum of the meridional overturning streamfunction in HadCM3. The maximum lies at $800 \mathrm{~m}$ depth and has a magnitude of $19 \mathrm{~Sv}\left(1 \mathrm{~Sv} \equiv 10^{6} \mathrm{~m}^{3} \mathrm{~s}^{-1}\right)$. Less than $1 \%$ of this occurs within the Ekman layer. The dynamics of the overturning circulation are thus overwhelmingly geostrophic in the area-mean. In Fig. 2 we show the ratio of the net ageostrophic force to the pressure-gradient force between 80 and $800 \mathrm{~m}$, i.e.

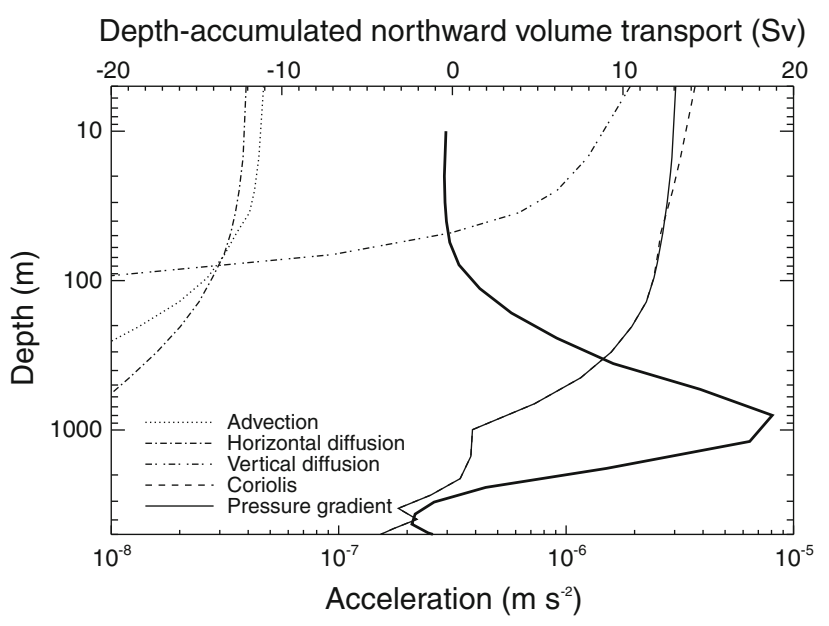

Fig. 1 Time-mean area-mean magnitude of terms in the equation of motion (thin lines, scale on the lower horizontal axis) as a function of depth in the Atlantic Ocean $30^{\circ} \mathrm{S}-70^{\circ} \mathrm{N}$, and northward volume transport (thick solid line, scale on the upper horizontal axis) through a section across the Atlantic Ocean at $35^{\circ} \mathrm{N}$ above the depth indicated on the vertical axis. The data is for the HadCM3 control climate 
Fig. 2 Ratio of the the magnitude of the vertically integrated net ageostrophic force (sum of advection, horizontal momentum diffusion and vertical momentum diffusion) to the magnitude of the vertically integrated pressure-gradient force. The vertical integral is taken between 80 and $800 \mathrm{~m}$ depth. The data is for the HadCM3 control climate

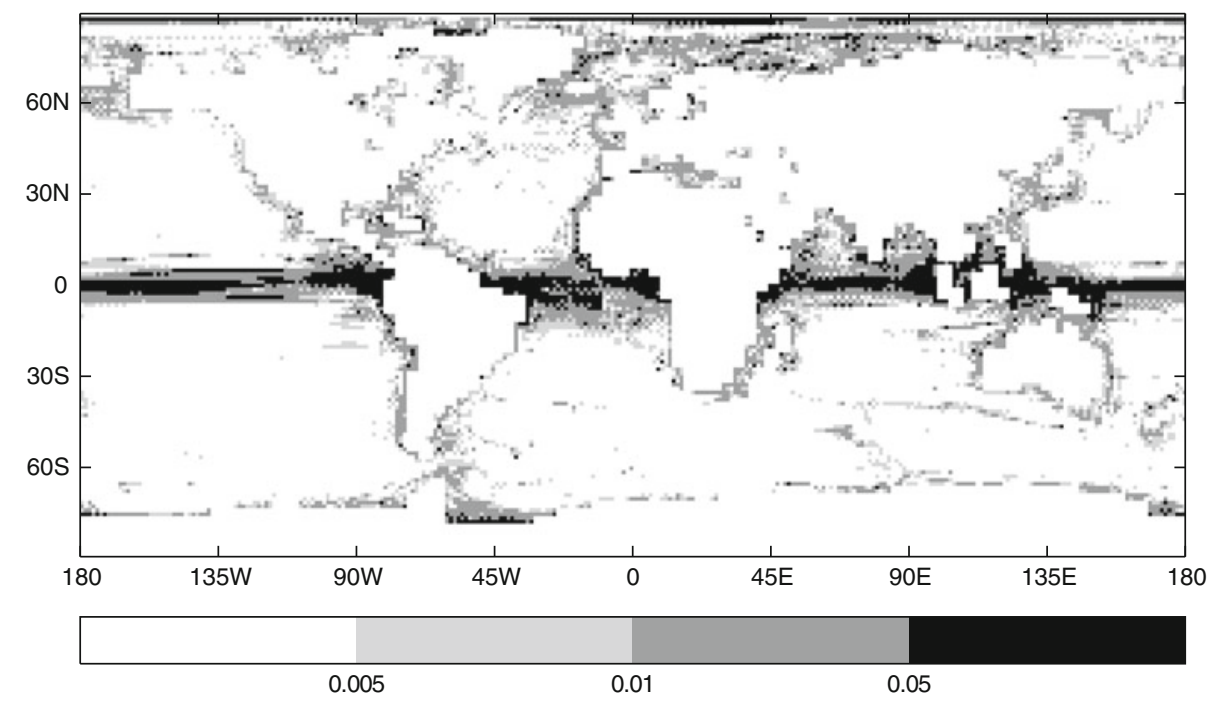

This is the fraction of $\nabla_{h} p$ which is not balanced by the Coriolis force. The depth range covers the upper branch of the AMOC, excluding the Ekman layer (cf. Fig. 1). At low latitudes, where the Coriolis force is weak, there are substantial regions where geostrophic balance does not hold. Apart from that, the ageostrophic component is less than 5\% almost everywhere; deviations occur in areas of shallow bathymetry. Even along the western boundary current of the Atlantic, flow is geostrophic; this is equally true of the southward deep western boundary current (not shown).

Consequently under global warming the proximate cause of the weakening of the AMOC must be a weakening of the zonal pressure gradient. However, this is not a satisfactory physical explanation; it raises further questions about the connection between zonal and meridional pressure gradients, and it does not easily lead us to a hypothesis relating the AMOC to meridional density gradients and buoyancy forcing. The difficulty is that geostrophy, while dominant as a dynamical balance, is irrelevant to the explanation of the driving forces of change. The advantage of an energetic analysis is that geostrophy is filtered out.

\section{Kinetic energy balance in the control climate}

\subsection{Terms in the KE balance}

Taking the scalar product of $\mathbf{u}_{h}$ with Eq. 1, we obtain an equation for the rate of change of specific kinetic energy $\frac{1}{2} u_{h}^{2}\left(\mathrm{~J} \mathrm{~kg}^{-1}=\mathrm{m}^{2} \mathrm{~s}^{-2}\right)$

$$
\begin{array}{r}
\mathbf{u}_{h} \cdot \frac{\partial \mathbf{u}_{h}}{\partial t}=\frac{\partial u_{h}^{2}}{\partial t 2}=-\underset{\text { advection }}{\mathbf{u}_{h} \cdot\left((\mathbf{u} \cdot \nabla) \mathbf{u}_{h}\right)}-\frac{1}{\rho_{0}} \mathbf{u}_{h} \cdot \nabla_{h} p \\
\text { pressure } \\
\text { gradient }
\end{array}
$$

The Coriolis term vanishes in the kinetic energy budget because the Coriolis acceleration is normal to the velocity, so $\mathbf{u}_{h} \cdot \mathbf{f} \times \mathbf{u}_{h}=0$.

There is no contribution from vertical velocity to the kinetic energy because according to the hydrostatic approximation there is never any net vertical force or acceleration. There is also no contribution relating to the eddy-induced transport velocity from the parametrisation of Gent and McWilliams (1990), which is used in some form in many models, including HadCM3 and FAMOUS. That is because the parametrisation does not enter the equation of motion (Eq. 1) and hence does not directly affect the budget of resolved kinetic energy in the model. Its effect is indirect, via the density field, by removing available potential energy (see Sect. 3.5). Gent et al. (1995) give an alternative formulation of the KE budget in which the resolved and eddy-induced velocities are combined.

The advective term $-\mathbf{u}_{h} \cdot\left((\mathbf{u} \cdot \nabla) \mathbf{u}_{h}\right)=-(\mathbf{u} \cdot \nabla) \frac{1}{2} u_{h}^{2}$, i.e. advection of scalar KE. The integral over the entire ocean volume of this term is zero, because advection conserves the scalar integral, as is easily demonstrated as follows. For any scalar $\chi$

$$
\nabla \cdot(\mathbf{u} \chi)=\chi \nabla \cdot \mathbf{u}+\mathbf{u} \cdot \nabla \chi
$$

Because the ocean is Boussinesq, volume is conserved rather than mass, so $\nabla \cdot \mathbf{u}=0$ and the first term on the right vanishes everywhere. Because there is zero normal 
velocity at all the boundaries, when integrated over entire ocean, the left-hand side $\nabla \cdot(\mathbf{u} \chi)$ vanishes by the divergence theorem. Hence the global integral

$$
\int \mathbf{u} \cdot \nabla \chi \mathrm{d} V=0
$$

for any scalar. Our model ocean uses the rigid-lid approximation, in which the surface is fixed at $z=0$, in order to suppress rapidly travelling external waves. In this approximation, there is really no vertical velocity at the surface by construction. In the real world, there is a nonzero volume flux through the surface due to precipitation and evaporation, but we presume the consequent KE flux is negligible.

The budget of globally integrated kinetic energy $K=$ $\int \frac{1}{2} \rho_{0} u_{h}^{2} \mathrm{~d} V$ is thus given by

$\frac{\mathrm{d} K}{\mathrm{~d} t}=B+\int \mathbf{u}_{h} \cdot\left(\mathbf{F}_{v}+\mathbf{F}_{h}\right) \mathrm{d} V$,

where $B=\int-\mathbf{u}_{h} \cdot \nabla_{h} p \mathrm{~d} V$ is the rate at which $\mathrm{KE}$ is added (or removed, if negative) by the pressure-gradient force, and the other terms arise from momentum diffusion. Locally, diffusion of momentum both transmits and dissipates KE (for instance, see Acheson 1990, Sect. 6.5), so diffusion and dissipation are not equal. When globally integrated, internal transmission sums to zero, as for advection, and only internal dissipation and external fluxes of KE remain. The vertical diffusion term $\int \mathbf{u}_{h} \cdot \mathbf{F}_{v} \mathrm{~d} V=W+$ $D_{v}$ is the sum of the KE input from the work done by the wind $W=\int \mathbf{u}_{h} \cdot \tau \mathrm{d} A$, and the interior dissipation $D_{v}$; there is no work done at the bottom, where there is no frictional stress (free slip). The horizontal diffusion term is purely dissipative $\int \mathbf{u}_{h} \cdot \mathbf{F}_{h} \mathrm{~d} V=D_{h}$, because there is no work done at the sides, where there is no lateral velocity (no slip) and hence no external KE flux. With these replacements, we obtain

$\frac{\mathrm{d} K}{\mathrm{~d} t}=B+W+D_{v}+D_{h}$,

corresponding to Eq. 8 of Toggweiler and Samuels (1998).

Since the models use the rigid-lid approximation, the pressure $p(z)=p_{s}+p_{\rho}(z)$, where $p_{s}$ is the pressure exerted by the rigid-lid at $z=0$, equivalent to the contribution from variable sea-level in the real world, and $p_{\rho}=$ $\int_{z}^{0} \rho\left(z^{\prime}\right) g \mathrm{~d} z^{\prime}$ is the weight of water below the rigid lid. The work done by the former is $\int-\mathbf{u}_{h} \cdot \nabla_{h} p_{s} \mathrm{~d} V$, but because $p_{s}$ is a surface field it has no vertical gradient, so

$$
\int-\mathbf{u}_{h} \cdot \nabla_{h} p_{s} \mathrm{~d} V=\int \mathbf{u} \cdot \nabla p_{s} \mathrm{~d} V=0
$$

by Eq. 3. In the global integral, the rigid-lid pressure gradient therefore does no work on the ocean. Hence for the global ocean $B$ can be evaluated from $p_{\rho}$ alone, without knowledge of $p_{s}$ (although we note that $p_{s}$ and $p_{\rho}$ are dynamically related, Lowe and Gregory 2006). On the other hand, for a limited area of the ocean, $\int-\mathbf{u}_{h} \cdot \nabla_{h} p_{s} \mathrm{~d} V$ does not vanish.

\subsection{Magnitude of terms in the global KE balance}

We have programmed separate diagnostics in our models for each of the named terms in Eq. 2, allowing us to quantify the global budget of $K$ in the control climate of HadCM3 and FAMOUS (top part of Table 1). The largest term is the input of KE from the wind, $W \simeq 3 \mathrm{TW}$ in HadCM 3 and $2 \mathrm{TW}$ in FAMOUS. These are substantially larger than most previous estimates. Those of Wunsch (1998) and Scott and Xu (2009) lie in the range $0.85-1 \mathrm{TW}$, but assume the surface velocity to be geostrophic. The results of Gnanadesikan et al. (2005) and Huang et al. (2006) show that including the ageostrophic velocity increases the estimate by $40-60 \%$; they obtain $W$ of 1.0-1.2 TW, although Urakawa and Hasumi (2009) obtained $W=0.8 \mathrm{TW}$. In an ocean model with much higher resolution of $0.1^{\circ}$, von Storch et al. (2007) calculated $W=3.8$ TW, 30\% larger than our result. Our diagnostic of $W$ uses the actual (not the geostrophic) surface velocity, and for an accurate result, $\mathbf{u}_{h} \cdot \tau$ is computed on each model timestep, because of the temporal covariation of the quantities. Using monthly means of $\mathbf{u}_{h}$ and $\tau$ gives $2.1 \mathrm{TW}$ in $\mathrm{HadCM} 3$, and the climatological annual means give $1.7 \mathrm{TW}$, underestimates of $W$ by 30 and $40 \%$. The spread of estimates suggests that the estimate of $W$ depends considerably on spatial and temporal resolution. High temporal resolution for this calculation may be particularly important in a coupled atmosphere-ocean model, which may have greater variability than an oceanonly model. We are unaware of any previously published value for $W$ from an AOGCM.

In HadCM3 and FAMOUS, about $55 \%$ of $W$ is dissipated by vertical diffusion of momentum in the Ekman layer (compare $D_{v}$ with $W$ in Table 1); von Storch et al. (2007) find that $70 \%$ of it is dissipated in their model. The majority of the remainder is dissipated by horizontal diffusion $\left(D_{h}\right)$. The advection term is diagnosed as zero, as it should be (not included in the table).

In the global mean, work is done against the pressure gradient $(B<0)$; in HadCM3 $B=-0.5 \mathrm{TW}$, and it is $\sim 10$ times smaller in FAMOUS. Toggweiler and Samuels (1998) first pointed out that $B<0$; in their model $B=-0.15 \mathrm{TW}$, while Gnanadesikan et al. (2005) found $B \simeq-0.6 \mathrm{TW}$, similar to HadCM3, and Urakawa and Hasumi (2009) $B=-0.25 \mathrm{TW}$. In this study, $B$ is the most important term; its sign is critical, as we see below.

Compared with any of the terms on the right of Eq. 4, $\mathrm{d} K / \mathrm{d} t$ is practically zero. The model ocean is strongly dissipative, its circulation maintained by continuous input of KE. Dividing $K$ by $W$ indicates a spin-up time of order $10^{6} \mathrm{~s}$, about ten days, implying that during climate change 
Table 1 Kinetic energy budget for the global ocean, and for the Atlantic and Arctic Oceans, in the AOGCMs HadCM3, FAMOUS (with its usual $12 \mathrm{~h}$ timestep) and FAMOUS with a $1 \mathrm{~h}$ timestep. The long-term time-mean budget for the control climate is shown above, with the rows marked \pm giving the standard deviation of decadal means. The difference in the budget with respect to the control is shown below for the final decade (years 131-140) of experiments in which $\mathrm{CO}_{2}$ increases at $1 \%$ per year, at the end of which it reaches four times the initial concentration. $B$ is generation of $\mathrm{KE}$ by the pressure-gradient force, $W$ work done by the wind, $D_{v, h}$ dissipation by vertical and horizontal (viscous) diffusion of momentum, and $Q$ loss of $\mathrm{KE}$ due to the numerical treatment of the Coriolis acceleration, all in TW $\left(10^{12} \mathrm{~W}\right)$, positive terms tending to increase KE. $K$ is the timemean $\mathrm{KE}$ in $\mathrm{EJ}\left(10^{18} \mathrm{~J}\right)$

\begin{tabular}{|c|c|c|c|c|c|c|}
\hline Model & $B$ & $W$ & $D_{v}$ & $D_{h}$ & $Q$ & $K$ \\
\hline \multicolumn{7}{|c|}{ Control climate, global ocean } \\
\hline HadCM3 & $-0.494 \pm 0.024$ & $2.870 \pm 0.032$ & $-1.559 \pm 0.011$ & $-0.782 \pm 0.010$ & $-0.034 \pm 0.000$ & $1.151 \pm 0.010$ \\
\hline FAMOUS & $-0.060 \pm 0.011$ & $2.416 \pm 0.028$ & $-1.310 \pm 0.012$ & $-0.747 \pm 0.013$ & $-0.292 \pm 0.004$ & $0.202 \pm 0.004$ \\
\hline FAMOUS $1 \mathrm{~h}$ & $-0.052 \pm 0.009$ & $1.993 \pm 0.023$ & $-1.119 \pm 0.010$ & $-0.793 \pm 0.011$ & $-0.028 \pm 0.000$ & $0.206 \pm 0.003$ \\
\hline \multicolumn{7}{|c|}{ Control climate, Atlantic and Arctic Ocean north of $30^{\circ} \mathrm{S}$} \\
\hline HadCM3 & $0.043 \pm 0.004$ & $0.334 \pm 0.004$ & $-0.213 \pm 0.002$ & $-0.160 \pm 0.005$ & $-0.005 \pm 0.000$ & $0.128 \pm 0.002$ \\
\hline FAMOUS & $0.075 \pm 0.004$ & $0.292 \pm 0.006$ & $-0.166 \pm 0.003$ & $-0.151 \pm 0.005$ & $-0.049 \pm 0.002$ & $0.023 \pm 0.001$ \\
\hline FAMOUS $1 \mathrm{~h}$ & $0.079 \pm 0.006$ & $0.224 \pm 0.004$ & $-0.135 \pm 0.002$ & $-0.163 \pm 0.008$ & $-0.004 \pm 0.000$ & $0.024 \pm 0.001$ \\
\hline \multicolumn{7}{|c|}{$4 \times \mathrm{CO}_{2}-$ control climate, global ocean } \\
\hline HadCM3 & -0.127 & 0.021 & 0.072 & 0.033 & 0.001 & 0.040 \\
\hline FAMOUS & -0.121 & -0.050 & 0.046 & 0.100 & 0.024 & -0.016 \\
\hline FAMOUS $1 \mathrm{~h}$ & -0.131 & -0.012 & 0.041 & 0.101 & 0.001 & -0.015 \\
\hline \multicolumn{7}{|c|}{$4 \times \mathrm{CO}_{2}-$ control climate, Atlantic and Arctic Ocean north of $30^{\circ} \mathrm{S}$} \\
\hline HadCM3 & -0.031 & -0.010 & 0.011 & 0.030 & 0.000 & -0.018 \\
\hline FAMOUS & -0.027 & -0.037 & 0.021 & 0.035 & 0.008 & -0.004 \\
\hline FAMOUS $1 \mathrm{~h}$ & -0.029 & -0.033 & 0.021 & 0.040 & 0.001 & -0.004 \\
\hline
\end{tabular}

on decadal timescales we can assume a KE balance always holds.

In addition to the terms of Eq. 2 for the KE budget, the models also have a non-zero Coriolis term $Q$ (Table 1), which physically ought to be zero. The Coriolis force is orthogonal to the velocity on the time-mean, as it should be, but it is not on individual timesteps. To arrange that accurately would require an implicit timestepping scheme for $\mathbf{u}_{h}$. In fact the model makes an approximation which tends to bias the Coriolis acceleration forwards in time, so inertial oscillation rotates it anticyclonically from its correct value. Thus, this numerical inaccuracy gives a spurious dissipation. In HadCM3 $|Q|$ is quite small, being $\sim 100$ times smaller than $W$ and $\sim 10$ times smaller than $|B|$, but in FAMOUS it is $\sim 10$ times larger than in HadCM3, on account of the longer timestep of $12 \mathrm{~h}$. We repeated the FAMOUS experiments with a timestep of $1 \mathrm{~h}$, as in HadCM3. This reduces $|Q|$ to its HadCM3 magnitude (Table 1). We have not found any statistically significant difference between the climate simulations of the two versions of FAMOUS, indicating that the greater energy loss does not materially affect our results.

\subsection{Latitudinal variation of terms in the global KE balance}

Examining the terms as a function of latitude (Fig. 3a, c, e), we find that the three models are qualitatively similar. At all latitudes, the spurious Coriolis term is negligible in HadCM 3 and in FAMOUS with the $1 \mathrm{~h}$ timestep, and small compared with other terms in FAMOUS with the usual long timestep. The two versions of FAMOUS show no important differences in other terms.

The input of KE by the wind has the greatest magnitude and is positive virtually everywhere. It is largest in the Southern Ocean and near the Equator. It is opposed everywhere by vertical dissipation. The horizontal diffusion term is negative everywhere as well, from which we infer it is locally dominated by horizontal dissipation; it is largest near the Equator and near $60^{\circ} \mathrm{S}$, where it too opposes the wind-work. The $\mathrm{KE}$ advection term (not shown) is locally small or negligible. As both advection and horizontal viscous transmission of $\mathrm{KE}$ are small, the $\mathrm{KE}$ balance is mostly local. Since the transport of KE is small but the dissipation is large, we could describe the model ocean as having a low Reynolds number.

The most important feature of the pressure-gradient term as a function of latitude is its negative contribution in the Southern Ocean, where it partly balances the input of KE by the wind. This effect makes $B<0$ in the global mean, outweighing contributions from latitudes where flow is being accelerated by the pressure gradient. As a function of depth, the global mean $B<0$ arises from negative $-\mathbf{u}_{h}$. $\nabla_{h} p$ in the near-surface layers (shown for HadCM3 in Fig. 4a). The horizontal diffusion term is dissipative 
Fig. 3 Zonally and vertically integrated terms in the kinetic energy balance of the model ocean, for the control climate and climate change. Note that the graphs have different scales on the ordinate. Generation of KE by the pressure-gradient force is shown in black, work done by the wind in red, dissipation of KE by vertical momentum diffusion in solid green, convergence and dissipation of KE by horizontal momentum diffusion in dashed green, and loss of KE due to the numerical treatment of the

Coriolis acceleration in blue.

Positive terms tend to increase KE
Control climate
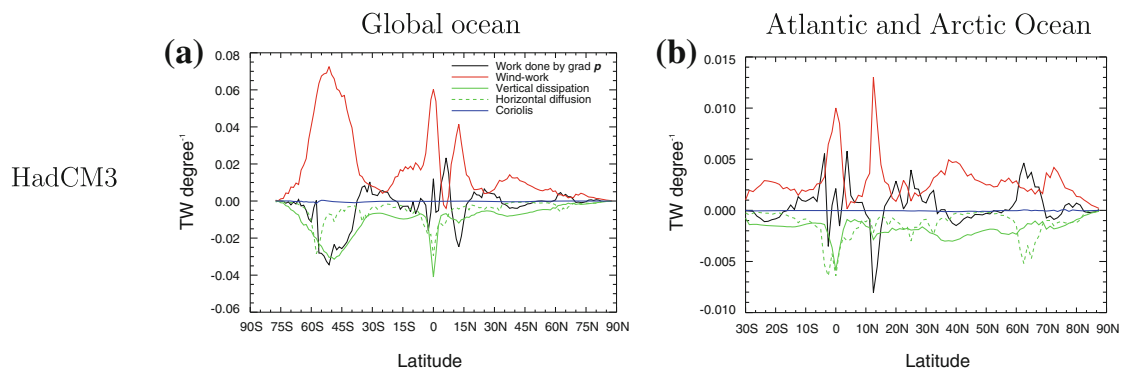

FAMOUS
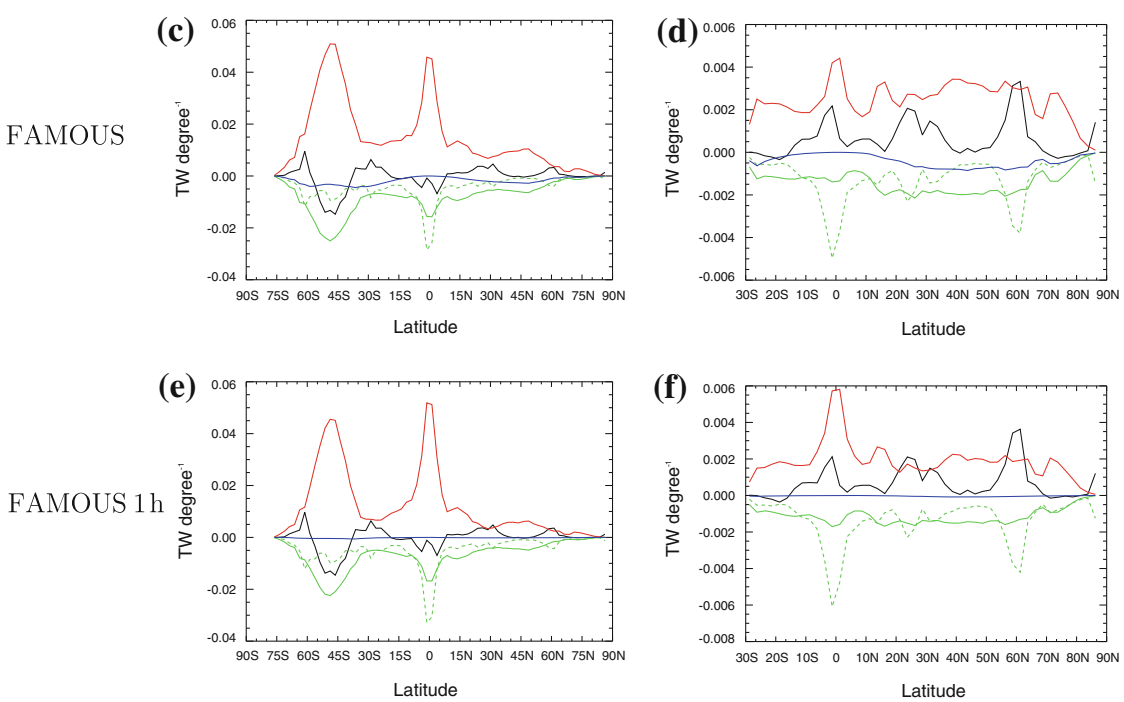

$4 \times \mathrm{CO}_{2}-$ control climate

HadCM3
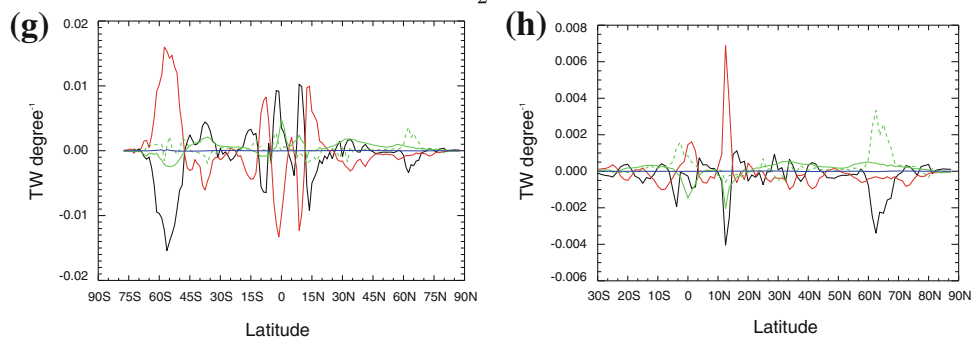

FAMOUS
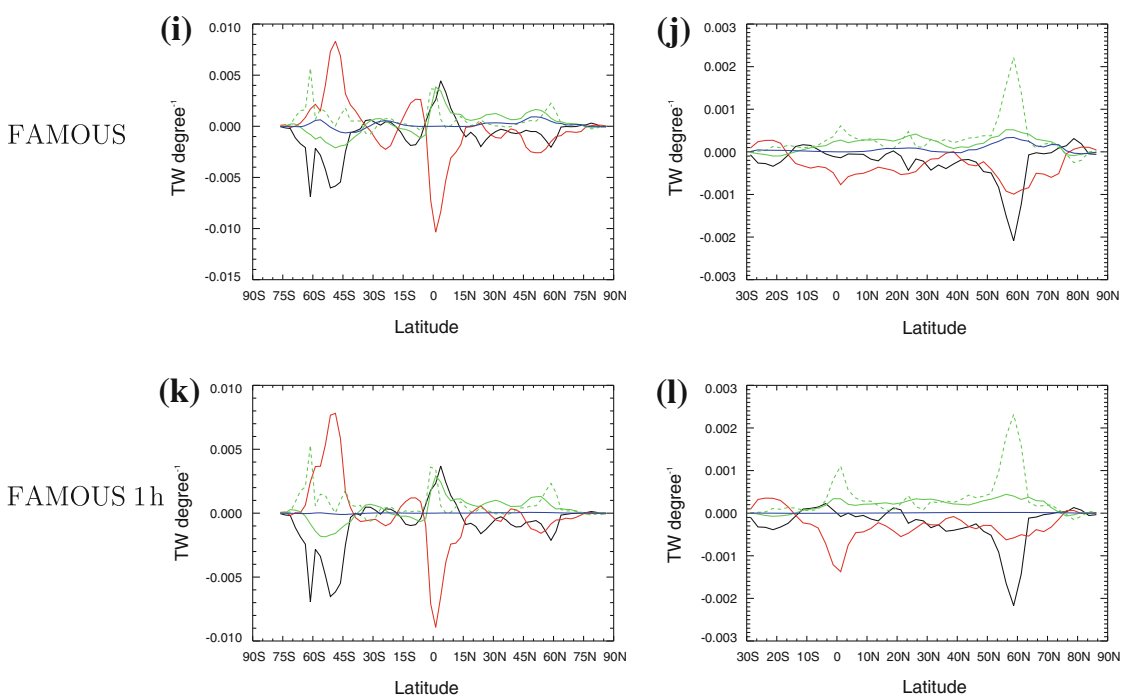

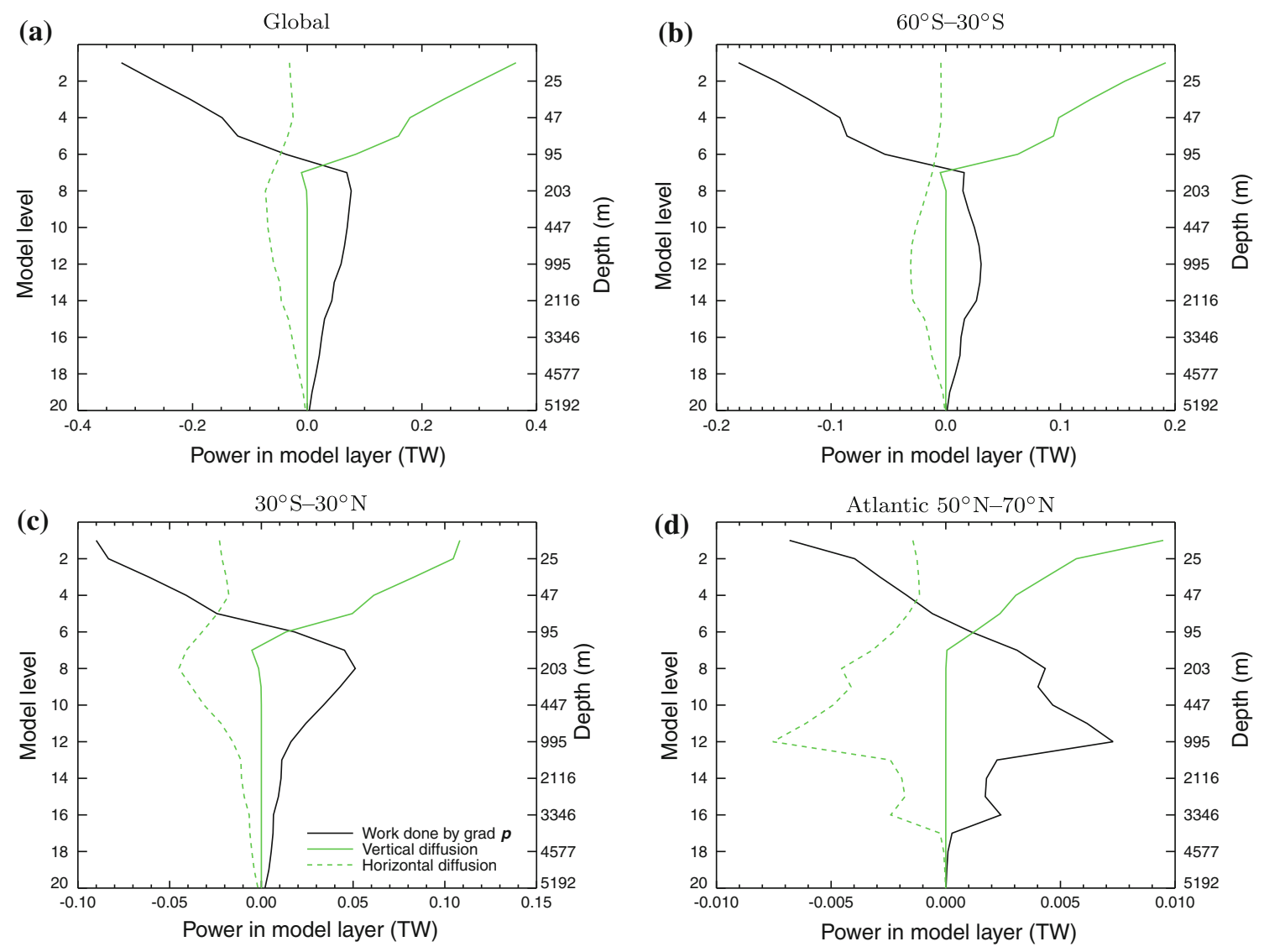

Fig. 4 Area-integral of terms in the kinetic energy balance of the HadCM3 ocean control climate. Note that the graphs have different scales on the abscissa. Generation of KE by the pressure-gradient force is shown in black, convergence and dissipation of KE by

vertical momentum diffusion in solid green, convergence and dissipation of $\mathrm{KE}$ by horizontal momentum diffusion in dashed green. Positive terms tend to increase KE

(negative) at all depths, as must be the case for its global area-integral. The vertical diffusion term is the sum of transmission and dissipation; it is positive within the Ekman layer, through which it spreads the KE input from the wind, and zero below.

Since $p_{\rho}$ is small near the surface, $\nabla_{h} p \simeq \nabla_{h} p_{s}$, so negative $-\mathbf{u}_{h} \cdot \nabla_{h} p$ in the surface layers means physically that water is moving up the sea-surface slope. This obtains over two-thirds of the world ocean area, including the Southern Ocean. It happens because the surface velocity has an ageostrophic component towards the centre of anticyclonic gyres, and away from the centre of cyclonic gyres, and both of these are "uphill". The Southern Ocean is an example of the latter; the circumpolar circulation is cyclonic and the Ekman transport is equatorward, in the direction of higher sea-level.

The sign of the depth-integrated $-\mathbf{u}_{h} \cdot \nabla_{h} p$ depends on the profiles of $\mathbf{u}_{h}(z)$ and $p(z)$. In the Southern Ocean, the meridional pressure gradient has the same sign (positive northward) at all depths and latitudes, but weakens in magnitude with increasing depth, as $p_{\rho}$ compensates for $p_{s}$. The southward return flow that balances the northward

Ekman flow occurs at depth and therefore experiences a smaller pressure gradient, making a relatively small positive contribution to $-\mathbf{u}_{h} \cdot \nabla_{h} p$, so the depth-integral is markedly negative (Fig. 4b). By contrast, at low latitudes the winddriven overturning (Ekman pumping and suction) is shallow, so the equal and opposite velocities in the Ekman layer and just below experience almost the same pressure gradient. Weak surface density gradients in these latitudes further reduce the contribution of $\nabla_{h} p_{\rho}$ to $\nabla_{h} p$ (Toggweiler and Samuels 1998). The surface and subsurface flows therefore make negative and positive contributions of similar size and the depth-integrated $-\mathbf{u}_{h} \cdot \nabla_{h} p$ is small (Fig. $4 \mathrm{c}$ ).

\subsection{KE balance in the Atlantic Ocean}

Our main interest in this paper is the Atlantic Ocean. For budgets and plots in the Atlantic we include the Arctic Ocean and the intervening seas, and we take the southern boundary of the Atlantic to be $30^{\circ} \mathrm{S}$, where it merges into the circumpolar Southern Ocean. Like in the global ocean, $W$ is the largest term, and is opposed by $D_{h, v}$, but unlike in the global ocean, $B$ is positive in the Atlantic, although 
Fig. 5 Rate of generation of $\mathrm{KE}$ by the pressure-gradient force $\left(\mathrm{mW} \mathrm{m}^{-2}\right) \int-\mathbf{u}_{h} \cdot \nabla_{h} p \mathrm{~d} z$ in the control climate of HadCM3 and FAMOUS

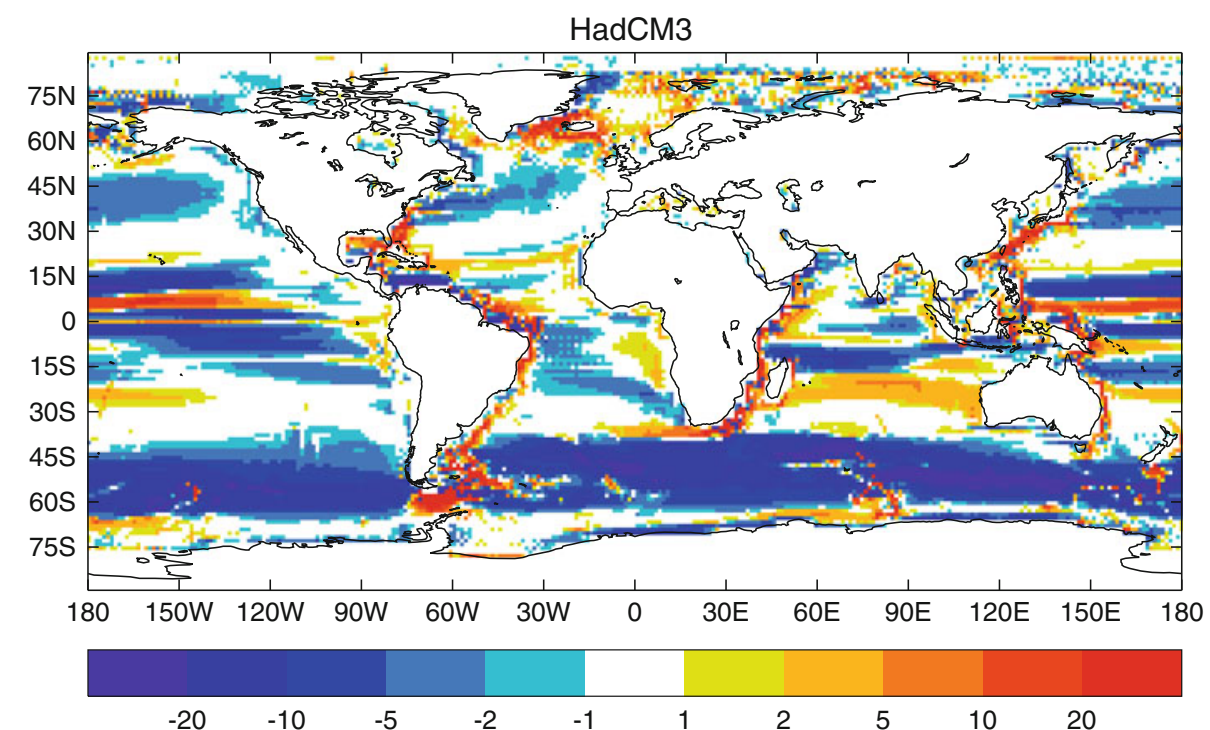

FAMOUS

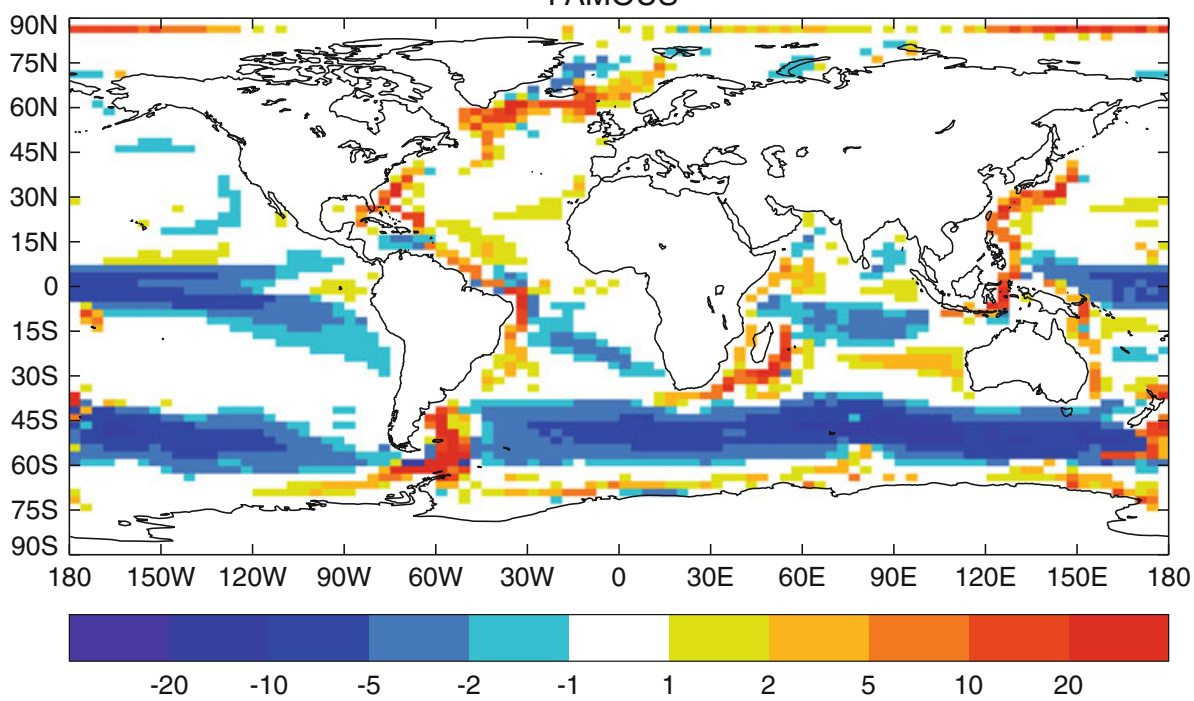

small compared with $W$. Atlantic $B=0.04 \mathrm{TW}$ in HadCM3, and twice the size in FAMOUS; Urakawa and Hasumi (2009) find 0.02 TW.

In HadCM3 $\iint-\mathbf{u}_{h} \cdot \nabla_{h} p \mathrm{~d} z \mathrm{~d} \phi>0$ at most latitudes in the Atlantic (Fig. 3b), and at practically all latitudes in FAMOUS (Fig. 3d, f); the main negative excursion in HadCM3 is a spike around $15^{\circ} \mathrm{N}$, where there is an overturning cell in which $B$ opposes the work of the wind, like in the Southern Ocean. The generally positive sign means that, in the Atlantic, the pressure-gradient force drives the circulation. The KE it generates is dissipated by horizontal diffusion at all latitudes; these two terms vary oppositely as a function of latitude. Particularly notable is the maximum of $\iint-\mathbf{u}_{h} \cdot \nabla_{h} p \mathrm{~d} z \mathrm{~d} \phi$ between $50^{\circ} \mathrm{N}$ and $70^{\circ} \mathrm{N}$, accompanied by a maximum in dissipation.

It is apparent from maps of $\int-\mathbf{u}_{h} \cdot \nabla_{h} p \mathrm{~d} z$ (Fig. 5) that $\mathrm{KE}$ is generated by the pressure-gradient force mainly within western boundary currents worldwide, including in the Atlantic, while work is done against the pressure gradient at almost all longitudes in the Southern Ocean. HadCM3 and FAMOUS have generally similar geographical distributions. HadCM3 has negative $\int-\mathbf{u}_{h} \cdot \nabla_{h} p \mathrm{~d} z$ along the North Atlantic Drift $30-45^{\circ} \mathrm{N}$. This feature does not appear in FAMOUS, perhaps because the current is less well defined at the lower resolution. The maximum in $50-70^{\circ} \mathrm{N}$ is accounted for by the regions where North Atlantic Deep Water is formed in the models, around Iceland, in the Norwegian Sea and in Baffin Bay, the latter in HadCM3 only.

In the area-integral over $50-70^{\circ} \mathrm{N}$ within the Atlantic, $\mathrm{KE}$ is generated at all depths below the Ekman layer (Fig. 4d), outweighing the negative contribution in upper layers from work done against the sea-surface slope. The zonally integrated flow is northward above $1000 \mathrm{~m}$ and 


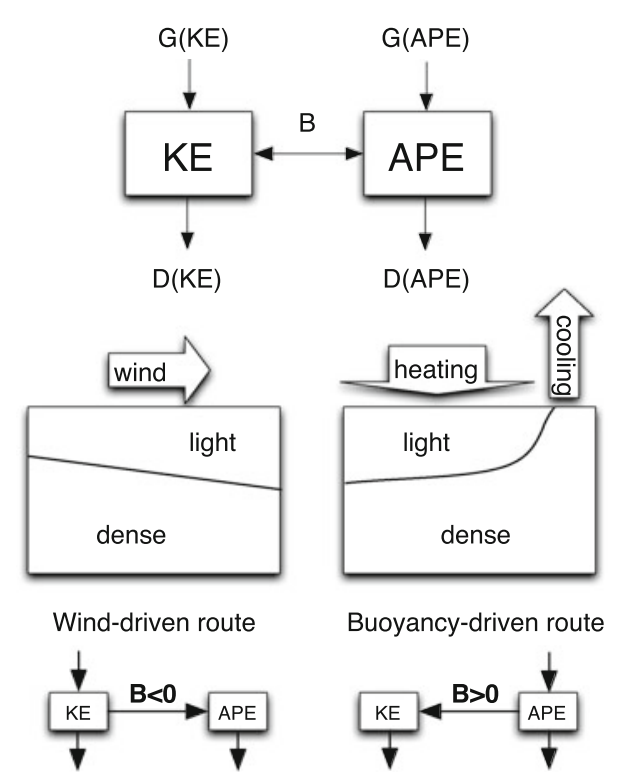

Fig. 6 Schematic depiction of the wind- and buoyancy-driven routes for energy conversion. $B$ is the conversion between resolved kinetic energy (KE) and available potential energy (APE), $G$ is generation, $D$ is dissipation

southward below (Fig. 1), but $-\mathbf{u}_{h} \cdot \nabla_{h} p>0$ throughout, because $\nabla_{h} p$ also reverses direction with depth. The pressure gradient thus does work on the AMOC. We have to keep in mind, however, that the circulation is very nearly geostrophic, as discussed above (Sect. 2). In the 3D ocean, the flow does not run down the pressure gradient, but almost at right-angles to it. Boundary friction causes dissipation of $\mathrm{KE}$, and changes the force balance so that the current is rotated slightly anticlockwise (cyclonically), towards the direction of the pressure-gradient force $-\nabla_{h} p$, thus making $-\mathbf{u}_{h} \cdot \nabla_{h} p>0$.

It is hard to identify a driving force of the AMOC because of the dominance of geostrophy in the momentum balance. However, geostrophy does not appear in the KE balance, which allows us to see that buoyancy forces supply energy to the circulation. This is evident from the latitudinal covariation of $-\mathbf{u}_{h} \cdot \nabla_{h} p$ and dissipation. Furthermore, the concentration of KE generation along the western boundary and in the deep north Atlantic strongly suggest that buoyancy forces supply KE to the AMOC. This is an inference from the control climate; in Sect. 4 we examine the relationship between KE and the AMOC during climate change.

\subsection{Potential energy}

In Sect. 3.3 we showed that $B<0$ on average in the global ocean, meaning that work is done against the pressuregradient force, especially in the Southern Ocean, and generally in near-surface layers where the wind-driven circulation runs up the sea-surface slope. In Sect. 3.4 we showed that $B>0$ in the Atlantic Ocean, meaning that work is done by the pressure-gradient force, especially in deeper layers, and its geographical distribution suggests that $\mathrm{KE}$ is being supplied to the AMOC. It is customary to interpret $B$ as the reversible conversion between resolved $\mathrm{KE}$ and available potential energy (APE). The opposite signs of $B$ are associated with different paths for energy conversion, as illustrated in Fig. 6, which is the energetics diagram used by Toggweiler and Samuels (1998) and more recently by Hughes et al. (2009).

The left-hand part of the diagram shows that the wind pushes fluid parcels adiabatically, pulling up dense parcels, and pumping down light parcels. This produces horizontal density variance and creates an opposing pressure gradient, providing a sink for the large-scale KE supplied by the wind, by converting it into APE $(B<0)$. A second sink of resolved $\mathrm{KE}$ is dissipation by the forward cascade (to smaller scales), parametrised as diffusion of momentum in ocean GCMs. The right-hand part of the diagram is associated with the diabatic creation of APE by surface buoyancy fluxes, which warm the ocean at low latitude and cool it at high latitude, generating density contrasts and thus a pressure-gradient force that causes motion and converts APE to KE $(B>0)$. A second sink of APE is dissipation by the forward cascade, represented in ocean OGCMs by mesoscale eddy parametrisations, especially Gent and McWilliams (1990). It is important to keep in mind that, for both signs of $B$, the steady-state circulation is almost normal to the pressure gradient, because the ocean is almost geostrophic. The magnitude of the buoyancy power input $G(A P E$ ) is a controversial topic (Munk and Wunsch 1998; Tailleux 2009), and especially whether it can be large. However, we note that $B$ is small compared with $W$ in our diagnosis of the Atlantic KE budget (Table 1) but nonetheless appears important in supplying $\mathrm{KE}$ to the AMOC (Sect. 3.4).

The global integral of $-\mathbf{u}_{h} \cdot \nabla_{h} p$ can be rewritten

$$
\begin{aligned}
B & =\int-\mathbf{u}_{h} \cdot \nabla_{h} p \mathrm{~d} V=-\int \mathbf{u} \cdot \nabla p-w \frac{\partial p}{\partial z} \mathrm{~d} z \\
& =-\int \rho g w \mathrm{~d} V
\end{aligned}
$$

where the first term on the right vanishes according to Eq. 3 and the hydrostatic approximation is applied to the second. Because $\int \rho g z \mathrm{~d} V$ is gravitational potential energy (GPE), $B$ has been interpreted as the rate of conversion of GPE to KE (Toggweiler and Samuels 1998). In a steady state, we might expect that $\int \rho w \mathrm{~d} A=0$ on any level $z$ i.e. zero net vertical mass flux, which would require that $B=0$. In a Boussinesq model, the steady-state $B$ can differ from zero because mass is not conserved, so the net vertical mass flux through any level can be non-zero. A steady-state 
Fig. 7 The difference between the $4 \times \mathrm{CO}_{2}$ and control climates of FAMOUS in the rate of generation of $\mathrm{KE}$ by the pressure-gradient force $-\mathbf{u}_{h}$. $\nabla_{h} p(\mathbf{a})$ integrated over depth $\left(\mathrm{mW} \mathrm{m}^{-2}\right.$ ) (b) zonally integrated over the Atlantic and Arctic basins and vertically integrated over layers of $500 \mathrm{~m}$ thickness (GW per degree of latitude), with the black line indicating the ocean bottom topography (a)
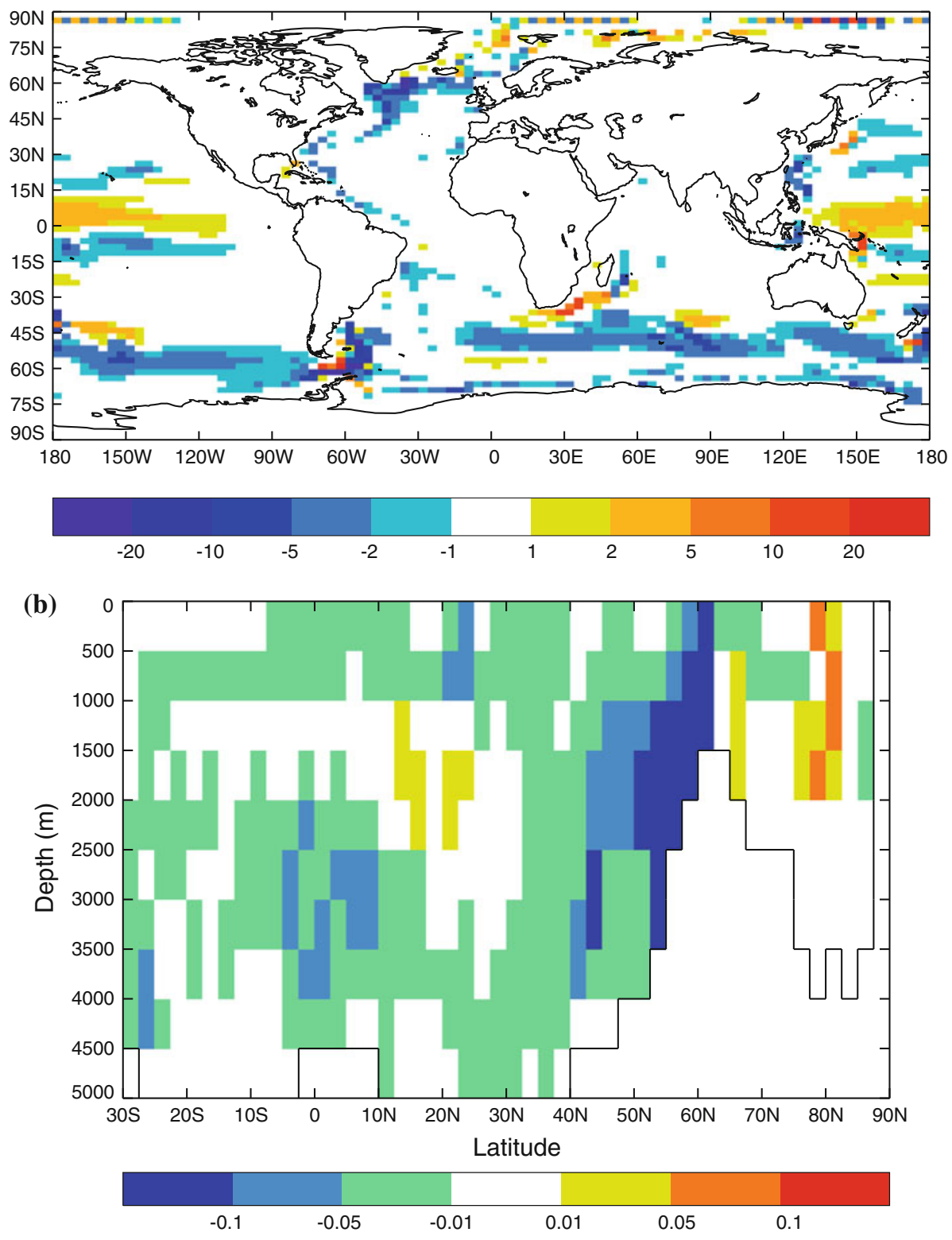

net conversion of KE to GPE $(B<0)$ means that denser water is moving upwards and less dense water downwards on the global average, with lighter water being converted to denser water at depth and vice-versa near the surface. The global integral is dominated by the Southern Ocean, as we saw above, where warm water is pumped downwards by the wind, cools at depth, and upwells with consequently greater density (Gregory 2000; Gnanadesikan et al. 2005; Wolfe et al. 2008). This gives a net upward mass flux and a gain of GPE, which is the sink of the KE supplied by the wind. In the Boussinesq world, the budget of potential energy is thus dominated by creation and destruction of mass. This complicates its interpretation. For the rest of this paper we restrict our attention to KE. Toggweiler and
Samuels (1998), Gnanadesikan et al. (2005) and Urakawa and Hasumi (2009) present analyses of the budget of potential energy in the ocean.

\section{KE balance and AMOC during climate change}

\subsection{Change to $\mathrm{KE}$ balance}

Under $\mathrm{CO}_{2}$-forced climate change, the $\mathrm{KE}$ balance is altered. We quantify the effect by evaluating the difference between the final decade (years 131-140) of experiments in which the atmospheric $\mathrm{CO}_{2}$ concentration increases at $1 \%$ per year, and the long-term mean of the 
control experiment. Since $\mathrm{CO}_{2}$ reaches four times its initial value after 140 years, we label the difference as "4 $\times \mathrm{CO}_{2}$-control".

Although the wind-work $W$ is the largest term in the control climate, the change in $W$ in the global KE balance is small (Table 1), and statistically insignificant by comparison with the standard deviation of decadal means in the control experiment. In the Atlantic and Arctic, $W$ declines significantly, but modestly (by less than 2\%). Examining the changes as a function of latitude (Fig. 3g, i, k) we see that the small net change in $W$ is the sum of an increase in the Southern Ocean and a decrease around the Equator. These correspond to increased and decreased near-surface wind-strength respectively. The reduced input of KE near the Equator is balanced by reductions in horizontal and vertical dissipation, i.e. $\Delta D_{v, h}>0$ because $D_{v, h}<0$ in the control, where $\Delta$ denotes the difference from the control. Saenko et al. (2005) similarly found a large increase in wind-work in the Southern Ocean under a climate of increasing $\mathrm{CO}_{2}$ in their AOGCM, but they do not see a reduction at low latitudes, with the result that they have a net increase in $W$. Possibly the difference arises because their calculation of $W$ uses geostrophic surface velocity.

The increased input of KE in the Southern Ocean leads to more work being done against the pressure gradient, so $B$ becomes more negative in that latitude band and in the global mean. If there was an immediate connection between APE generated by winds in the Southern Ocean and converted to KE in the Atlantic, as Toggweiler and Samuels (1998) suggest for the steady state, an increase in $|B|$ would tend to strengthen the AMOC, not to weaken it, as actually happens.

By contrast, in the Atlantic (Fig. 3h, j, l), the most marked change in the KE balance is a reduction in the peak of positive $\iint-\mathbf{u}_{h} \cdot \nabla_{h} p \mathrm{~d} z \mathrm{~d} \phi$ in $50-70^{\circ} \mathrm{N}$, mirrored by a reduction in horizontal dissipation. The reduction in $-\mathbf{u}_{h}$. $\nabla_{h} p$ is strongest in the north Atlantic (Fig. 7a; HadCM3 is similar), and is greatest in the lower layers, where the southward branch of the AMOC descends the slopes of the ridges between Greenland and Scotland (Fig. 7b; HadCM3 is similar). FAMOUS shows a reduction in $\int-\mathbf{u}_{h}$. $\nabla_{h} p \mathrm{~d} z \mathrm{~d} \phi$ at most other latitudes, with smaller magnitude, while HadCM3 has small changes of both signs. Overall in both models the result is a large and significant reduction in the Atlantic $B$ (Table 1), while the reduction in $W$ is relatively small. If less KE is supplied, dissipation must be reduced to match (as we see from the diagnostics), and it is likely that the circulation has to "slow down" in some way to achieve this reduction. We hypothesise that the reduced $\mathrm{KE}$ input from work done by the pressure gradient in the Atlantic, especially in the northern region of deep water formation, is balanced by reduced dissipation associated with weakening of the AMOC.

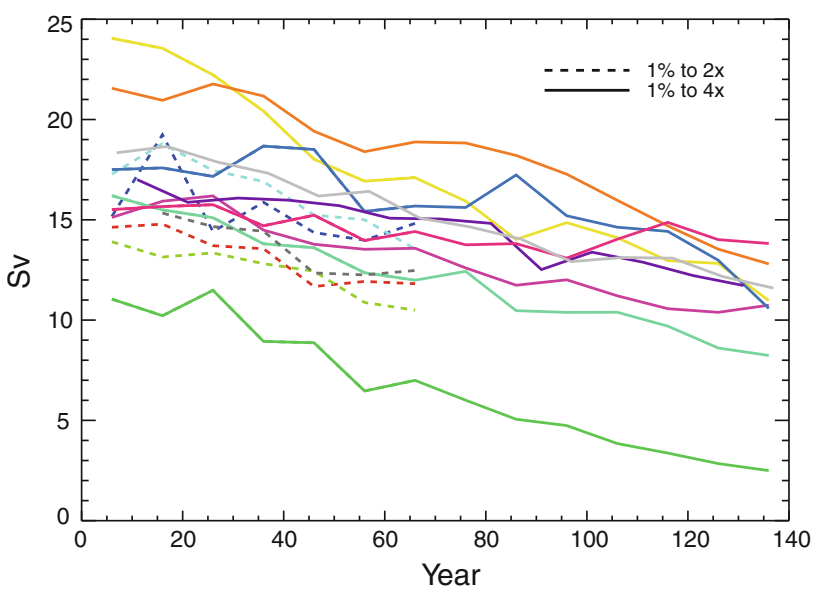

Fig. 8 Timeseries of maximum over depth of the Atlantic meridional overturning streamfunction at $45^{\circ} \mathrm{N}$ in decadal means from CMIP3 AOGCMs with $\mathrm{CO}_{2}$ increasing at $1 \%$ year $^{-1}$ up to twice its initial concentration (70 years) or four times (140 years)

\subsection{Relationship of AMOC and $B$ during climate change}

Our hypothesis suggests that there should be a relationship between the AMOC strength and $B$ as climate changes. We test the hypothesis using results from the CMIP3 AOGCMs under the same scenario as our above analysis of HadCM3 and FAMOUS, namely a $1 \%$ year $^{-1}$ increase in atmospheric $\mathrm{CO}_{2}$. This is an idealised scenario with a rate of increase of radiative forcing of the approximate size projected to occur during the twenty-first century in the absence of climate-change mitigation. For analysis of physical mechanisms it has the advantage that the radiative forcing it produces is more nearly model-independent than the forcing from detailed socioeconomic scenarios such A1B and the other SRES scenarios of Nakićenović et al. (2000), because they include anthropogenic aerosol forcing, which is substantial and much more uncertain than the forcing due to $\mathrm{CO}_{2}$. Therefore under the $1 \%$ year $^{-1}$ scenario the different projections of models can be attributed to uncertainty in climate response rather than in forcing.

The AMOC strength can be measured in various ways. A conventional choice for AOGCM analysis is to evaluate the Atlantic meridional overturning streamfunction from the northward velocity $v$

$\Psi(\lambda, z, t)=\int_{\text {Atlantic }} \int_{z}^{0} v\left(\phi, \lambda, z^{\prime}, t\right) \mathrm{d} z^{\prime} \mathrm{d} \phi$

and for each time $t$ to find the maximum value $M^{\max }(t)$ within a latitude range for the Atlantic basin and a depth range excluding shallow wind-driven circulations (for instance 500-2,000 m). A positive $M^{\max }$ means northward flow above the depth of the maximum and southward flow below. 
The latitude of $M^{\max }(t)$ is model- and time-dependent. Since this could be a confusing factor in our quantitative model intercomparison of AMOC energetics, we prefer to choose a fixed latitude. We define $M(t)$ as the maximum over $z$ of $\Psi$ for a constant $\lambda$. A suitable choice for $\lambda$ is $45^{\circ} \mathrm{N}$, since for majority of models this is near to the latitude of largest decline in $M$. Note that this is not necessarily the latitude of $M^{\max }$ in the control climate. Using $M$ at $45^{\circ} \mathrm{N}$, we see that while $\mathrm{CO}_{2}$ increases the AMOC declines, by various amounts, in all CMIP3 models for which we have data (Fig. 8). Most of the AOGCMs give results for 140 years, up to four times the initial $\mathrm{CO}_{2}$ concentration, but a few give results for only 70 years, up to twice the initial concentration.

To test the hypothesis, we need also to compute $-\mathbf{u}_{h} \cdot \nabla_{h} p$, which is not a standard model diagnostic in the CMIP3 database. The database provides $\mathbf{u}_{h}, \rho$ and sea-level $\eta$, which is simply related to $p_{s}=\rho_{0} g \eta$ for both rigid-lid models and models with a free surface. Some models have been omitted from this study because the CMIP3 database did not contain all the necessary diagnostics. The highest temporal resolution available in the database for the relevant quantities is monthly means. Because $-\mathbf{u}_{h} \cdot \nabla_{h} p$ is a product of variables, calculating it from monthly means of $\mathbf{u}_{h}$ and $p$ will not necessarily give an accurate estimate of its true time-mean. However, on the basis of results discussed below, we conclude that annual means are adequate for our purposes. We computed annual-mean $B$ from annual-mean $\mathbf{u}_{h}$ and $p$, and decadal-mean $B$ from annualmean $B$.

The AMOC is a large-scale phenomenon with longrange correlation (cf. Bingham and Hughes 2009b). Therefore to decide on the volume over which $-\mathbf{u}_{h} \cdot \nabla_{h} p$ should be integrated, we computed $B$ in the Atlantic and Arctic for all contiguous latitude bands that have southern and northern boundaries at multiples of $5^{\circ}$ between $30^{\circ} \mathrm{S}$ and $90^{\circ} \mathrm{N}$. Thus, the widest range considered is $30^{\circ} \mathrm{S}-$ $90^{\circ} \mathrm{N}$, and the narrowest ranges are $5^{\circ}$ bands $30^{\circ} \mathrm{S}-25^{\circ} \mathrm{S}$, $25^{\circ} \mathrm{S}-20^{\circ} \mathrm{S}, \ldots, 85^{\circ} \mathrm{N}-90^{\circ} \mathrm{N}$. We also computed $B$ for the global ocean, and for the ocean south of $30^{\circ} \mathrm{S}$. In the GFDL AOGCMs, the ocean model has a tripolar grid, in which grid lines and velocity components are not lines of latitude and longitude north of $65^{\circ} \mathrm{N}$. Since this complicates the computation of $M$ and $B$, we excluded the area north of this latitude for those two models.

For each model, we correlated decadal-mean AMOC strength $\left(M\right.$ at $\left.45^{\circ} \mathrm{N}\right)$ with decadal-mean $B$ for every region. The correlation $r_{M B}$ as a function of region is quite strongly model-dependent, but of the ten CMIP3 models we considered (including HadCM3), all but two give good correlations for many different choices of region; we exclude those two (BCCR-BCM2.0 and ECHO-G) from subsequent analysis. Their low correlations could be due to

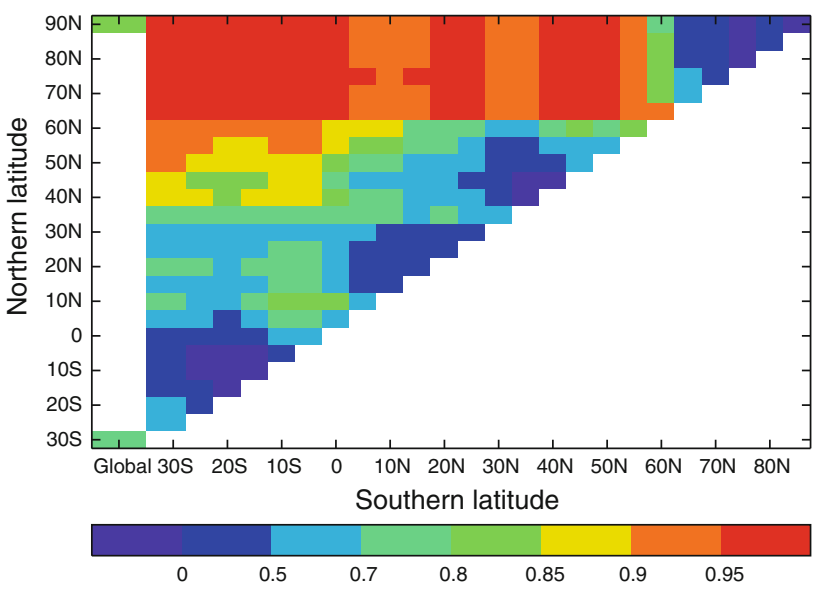

Fig. 9 Average across nine models of the correlation between decadal-mean AMOC strength and decadal-mean $B$ from integrations with $\mathrm{CO}_{2}$ increasing at $1 \%$ year $^{-1} . B$ is computed for various latitude ranges within the Atlantic, with southern and northern limits as shown on the axes, and for the global ocean (top left point) and the global ocean south of $30^{\circ} \mathrm{S}$ (bottom left point)

inadequacies of the data available. The CMIP3 diagnostics were not designed for purposes such as this analysis. For instance, horizontal and vertical interpolation are necessary in some cases, which introduces inaccuracy. In some models the sea-level $\eta$ diagnostic does not allow us to calculate $\nabla_{h} p_{s}$ at all points where $\mathbf{u}_{h}$ exists. For models in which $\eta$ is not a prognostic, the method by which it was derived may not be accurate enough. One such is model is HadCM3; we agree with Bingham and Hughes (2009a) that the $p_{s}$ fields for HadCM3 are inaccurate, though they are adequate for their intended purpose of studying sea-level change. In HadCM3, the problem arises from the numerical method used to obtain $p_{s}$ from $\nabla_{h} p_{s}$ (Gregory et al. 2001). The latter quantity is the one needed in the present analysis, and we obtain it directly as a model diagnostic from HadCM 3 and FAMOUS in order to avoid the problem.

The remaining nine models (eight CMIP3 and FAMOUS) give correlation coefficients $r_{M B}$ exceeding 0.85 provided the region extends northwards at least to $65^{\circ} \mathrm{N}$ (Fig. 9). In some cases, extending the region southward improves the correlation, in others a narrow northern region is best. The model-average of $r_{M B}$ is $\geq 0.95$ and its inter-model standard deviation is $\leq 0.05$ for nearly all regions with a southern boundary at or south of $50^{\circ} \mathrm{N}$, and a northern boundary at $70^{\circ} \mathrm{N}$; including more of the Arctic slightly reduces $r_{M B}$. We therefore choose the north Atlantic region $50-70^{\circ} \mathrm{N}$ to evaluate $B$. We find that in most of the CMIP3 models, as in HadCM3 and FAMOUS, the largest reduction in $-\mathbf{u}_{h} \cdot \nabla_{h} p$ is found around $60^{\circ} \mathrm{N}$, where it extends to deep layers. The model-average $r_{M B}$ with $B$ integrated over the global ocean, or over the Southern Ocean, is substantially lower than for north 
Fig. 10 Decadal-mean AMOC strength (Sv) at $45^{\circ} \mathrm{N}$ plotted against decadal-mean KE generation $B(\mathrm{GW})$ by the pressure-gradient force integrated over the Atlantic 50 $70^{\circ} \mathrm{N}$. The plus symbols are for the integrations with $\mathrm{CO}_{2}$ increasing at $1 \%$ year $^{-1}$. For most models, these integrations are 140 years long, up to $4 \times \mathrm{CO}_{2}$. The cross symbols are for integrations under scenario SRES A1B. As time passes, $M$ and $B$ decline together. The lines are regressions, solid for the $1 \%$ year $^{-1}$ scenario, dashed for A1B. The diamonds are for control integrations with preindustrial forcing. Note that the plots have different scales
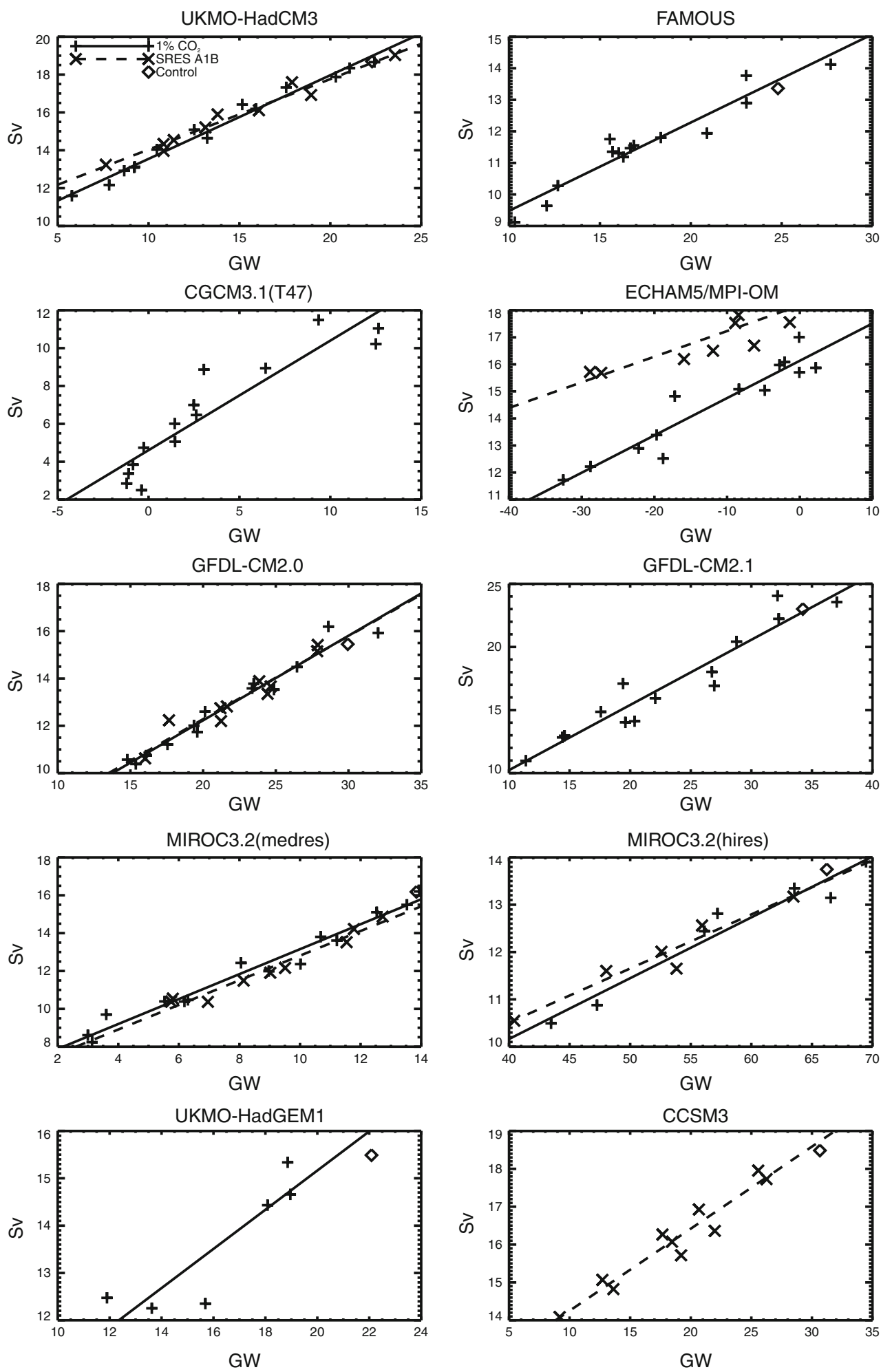

Atlantic regions, agreeing with our expectation that changes in the AMOC are related primarily to changes in the north Atlantic. This is true in most of the individual models as well, including MIROC 3.2 (hires), which is the only eddy-permitting ocean model in CMIP3. (In the steady state, however, Spence et al. (2009) suggest that such a model may have a qualitatively different connection between the Southern Ocean overturning and the AMOC from models in which the effect of eddies is parametrised.)

For each of the models, we plot decadal-mean $M$ against $B$ (plus symbols in Fig. 10) and calculate the slope $\mathrm{d} M / \mathrm{d} B$ of their relationship by linear regression (Table 2 and solid 
Table 2 Statistics of $M$ (the AMOC strength at $45^{\circ} \mathrm{N}$, in Sv), $B$ (the generation of KE by the pressure-gradient force in the Atlantic $50-70^{\circ} \mathrm{N}$, in $\mathrm{GW}$ ) and the relationship between them in experiments with $\mathrm{CO}_{2}$ increasing at $1 \%$ year ${ }^{-1}$, and under the SRES A1B scenario for the twenty-first century

\begin{tabular}{|c|c|c|c|c|c|c|c|c|c|}
\hline \multirow[t]{2}{*}{ Model } & & \multicolumn{2}{|c|}{ Control } & \multicolumn{4}{|c|}{$1 \%$ year $^{-1} \mathrm{CO}_{2}$} & \multicolumn{2}{|c|}{ SRES A1B } \\
\hline & & $M$ & $B$ & $\sigma(M)$ & $\sigma(B)$ & $r_{M B}$ & $\mathrm{~d} M / \mathrm{d} B$ & $r_{M B}$ & $\mathrm{~d} M / \mathrm{d} B$ \\
\hline \multirow[t]{2}{*}{ UKMO-HadCM3 } & \multirow[t]{2}{*}{ A } & \multirow[t]{2}{*}{18.7} & 22.3 & \multirow[t]{2}{*}{2.4} & 5.3 & 0.99 & 0.44 & \multirow[t]{2}{*}{0.98} & \multirow[t]{2}{*}{0.37} \\
\hline & & & 24.2 & & 6.2 & 0.99 & 0.38 & & \\
\hline \multirow[t]{2}{*}{ FAMOUS } & \multirow[t]{2}{*}{$\mathrm{B}$} & \multirow[t]{2}{*}{13.4} & 24.8 & \multirow[t]{2}{*}{1.4} & 4.8 & 0.96 & 0.28 & & \\
\hline & & & 28.1 & & 5.0 & 0.96 & 0.27 & & \\
\hline \multirow[t]{2}{*}{ FAMOUS (1 h) } & \multirow[t]{2}{*}{$\mathrm{C}$} & \multirow[t]{2}{*}{13.8} & 27.3 & \multirow[t]{2}{*}{1.6} & 6.4 & 0.98 & 0.24 & & \\
\hline & & & 29.1 & & 6.7 & 0.98 & 0.23 & & \\
\hline CGCM3.1(T47) & $\mathrm{D}$ & 11.0 & 12.6 & 3.1 & 4.9 & 0.92 & 0.58 & & \\
\hline ECHAM5/MPI-OM & $\mathrm{E}$ & 17.0 & -0.1 & 1.7 & 11.8 & 0.95 & 0.14 & 0.80 & 0.09 \\
\hline GFDL-CM2.0 & $\mathrm{F}$ & 15.5 & 29.9 & 2.0 & 5.3 & 0.98 & 0.36 & 0.96 & 0.35 \\
\hline GFDL-CM2.1 & G & 23.0 & 34.2 & 4.2 & 7.7 & 0.95 & 0.52 & & \\
\hline MIROC3.2 (medres) & $\mathrm{H}$ & 16.2 & 13.8 & 2.5 & 3.8 & 0.98 & 0.66 & 0.99 & 0.65 \\
\hline MIROC3.2 (hires) & I & 13.7 & 66.2 & 2.6 & 19.4 & 0.97 & 0.13 & 0.99 & 0.11 \\
\hline UKMO-HadGEM1 & $\mathrm{J}$ & 15.5 & 22.1 & 2.8 & 5.9 & 0.89 & 0.41 & & \\
\hline CCSM3 & $\mathrm{K}$ & 18.5 & 30.7 & & & & & 0.96 & 0.22 \\
\hline $\mathrm{CV}$ excluding $\mathrm{C}$ & & 0.22 & 0.77 & 0.33 & 0.65 & 0.04 & 0.47 & & \\
\hline $\mathrm{CV}$ excluding $\mathrm{C}, \mathrm{E}$ and $\mathrm{I}$ & & 0.25 & 0.36 & 0.34 & 0.22 & 0.04 & 0.28 & & \\
\hline
\end{tabular}

The values of $M$ and $B$ are the average of the part of the control experiment parallel to the $1 \%$ year ${ }^{-1} \mathrm{CO}_{2}$ experiment, except for CGCM3.1(T47) and ECHAM5/MPI-OM, for which not all the required control data are available so $M$ and $B$ are evaluated instead from the first decade of the $1 \%$ year ${ }^{-1} \mathrm{CO}_{2}$ experiment. The columns marked $\sigma_{M, B}$ are the standard deviations of decadal-mean $M$ and $B, r_{M B}$ the correlation coefficients between decadal-mean $M$ and $B$, and $\mathrm{d} M / \mathrm{d} B$ (in $\mathrm{Sv} \mathrm{GW}^{-1}$ ) the slopes of the regression of $M$ against $B$. The $\mathrm{CO}_{2}$ experiments with MIROC3.2 (hires) and UKMO-HadGEM1 were 70 years long, up to $2 \times \mathrm{CO}_{2}$, and the others 140 years long, up to $4 \times \mathrm{CO}_{2}$. To make the statistics comparable, $\sigma_{M, B}$ have been doubled for the $2 \times \mathrm{CO}_{2}$ experiments. The second lines for HadCM3, FAMOUS and FAMOUS (1 h) give statistics computed using $B$ calculated from a model diagnostic of $-\mathbf{u}_{h} \cdot \nabla_{h} p$, whereas the first lines give the results for $B$ calculated from annual-mean $\mathbf{u}_{h}$ and $p$, as for all the other models. The bottom lines of the table give the inter-model coefficient of variation in some quantities for the $\mathrm{CO}_{2}$ experiments

lines in Fig. 10). Because we are not subtracting the control in parallel from the $1 \%$ year $^{-1}$ integration, changes in $M$ and $B$ include any ongoing climate drift in the model, due to insufficient spinup. Timeseries of $M$ indicate that this is not significant except for CGCM3.1(T47), in which $M$ declines by about $3 \mathrm{~Sv}$ in the control integration during the period corresponding to the $1 \%$ year $^{-1}$ integration.

The correlation between $M$ and $B$ is evidently due largely to the monotonic effect of climate change on both quantities, but the uneven spacing of the symbols along the regression lines shows that there is also correlated interdecadal variability. Since the trend is dominant, we can measure the magnitude of the change in $M$ and $B$ during the experiment by the standard deviations $\sigma(M)$ and $\sigma(B)$ of their decadal means (Table 2). The standard deviation indicates the spread of values, so a large decrease in $M$ over time will give a large $\sigma(M)$, for example. We use standard deviations within the climate-change experiment, instead of the more usual method of calculating differences with respect to the control integration, because the CMIP3 database does not include $\mathbf{u}_{h}$ for the control of all the models we are using, so we cannot calculate the control values in all cases. However, using the standard deviation to measure the change also has the advantage that it depends on all values in the timeseries, and is hence a more robust statistic than the final value alone. If a quantity $\chi(t)$ changes linearly in time, its temporal standard deviation during an interval $T$

$$
\begin{aligned}
\sigma(\chi) & =\sqrt{\frac{1}{T} \int_{0}^{T}\left(\frac{\mathrm{d} \chi}{\mathrm{d} t}\left(t-\frac{T}{2}\right)\right)^{2} \mathrm{~d} t}=\frac{\mathrm{d} \chi}{\mathrm{d} t} \sqrt{\frac{1}{T} T^{3}\left(\frac{1}{3}-\frac{1}{2}+\frac{1}{4}\right)} \\
& =\frac{T \mathrm{~d} \chi}{2 \sqrt{3} \mathrm{~d} t}
\end{aligned}
$$

is $1 /(2 \sqrt{3})=29 \%$ of its change $T \mathrm{~d} \gamma / \mathrm{d} t$ due to the trend during the interval. For the $1 \%$ year $^{-1} \mathrm{CO}_{2}$ integrations in Table 2, $\sigma(M) / M$ implies a weakening of the AMOC at $4 \times \mathrm{CO}_{2}$ in the range 35-65\%, except for CGCM3.1(T47), which weakens by more because the AMOC is spinning down even in the control.

We investigate how the accuracy of the estimate of $B$ is degraded by the use of time-means for $\mathbf{u}_{h}$ and $p$ by comparison with our accurate calculation of $-\mathbf{u}_{h} \cdot \nabla_{h} p$ as a 
model diagnostic in HadCM3 and FAMOUS. The calculation of $B$ from annual means is tolerably accurate (Table 2). The correlation of $M$ with $B$ computed from annual-mean data is nearly as high as with $B$ when directly diagnosed, and most importantly the differences between methods are small for $\sigma(B)$ and $\mathrm{d} M / \mathrm{d} B$ (Table 2), compared with the inter-model standard deviations in these quantities. The results may be insensitive to the use of annual means because the most important contributions to changes in $B$ come from the deeper layers of the ocean, where there is less subannual variability (Fig. 7b). We find that for most CMIP3 models we get very similar results for $B$ from monthly and annual-mean data (ECHAM5-MPI/OM is an exception, discussed below). Hence we argue that annual means from CMIP3 data are adequate for this analysis. Although precise KE diagnostics from other models would be of great interest for studying the KE budget, it is likely that our estimates of $B$ from annual means are reasonable. We note that all models (again, except for ECHAM5/MPI$\mathrm{OM}$ ) give $B>0$ in the north Atlantic (Table 2; see also Sect. 4.3). By contrast, there is large short-period variability in surface quantities, so $W$ can be estimated accurately only from high-frequency data, as shown above (Sect. 3.2), and therefore cannot be obtained from the CMIP3 database.

The correlation of $M$ and $B$ might arise because $M$ is a large-scale measure of the velocity field, and the velocity also appears in $-\mathbf{u}_{h} \cdot \nabla_{h} p$. In that case the relationship would not indicate a physical link to $p$. To test this possibility, we also calculated

$B_{p}(t)=\int-\overline{\mathbf{u}_{h}} \cdot \nabla_{h} p(t) \mathrm{d} V$

where $\overline{\mathbf{u}_{h}}$ is the time-mean velocity during the $1 \%$ year $^{-1}$ experiment up to $4 \times \mathrm{CO}_{2}$. The time-dependence of $B_{p}$ comes only from $p$, and in most of the models $B_{p}$ also correlates well with $M$, indicating that the variation of $M$ is really related to $p$, although the relationship is generally weaker than with $B$. We also calculated the correlation of $M$ with

$B_{u}(t)=\int-\mathbf{u}_{h}(t) \cdot \nabla_{h} \bar{p} \mathrm{~d} V$,

where $\bar{p}$ is the time-mean of $p$. Only one model gives a strong positive correlation of $M$ with $B_{u}$.

As discussed in Sect. 1, Thorpe et al. (2001) found a correlation of the AMOC in HadCM3 with the meridional density gradient in the Atlantic. They considered a wide range of experiments, encompassing a much larger decrease in $M$ than occurs in the CMIP3 experiments. For 150 years of the 2PC experiment of Thorpe et al. (2001), in which $\mathrm{CO}_{2}$ increased at $2 \%$ year $^{-1}$ up to 20 times its initial value, we obtain a correlation between decadal-mean $M$ and $-\mathbf{u}_{h}$. $\nabla_{h} p$ of 0.98 , higher than the correlation they found of 0.92 between decadal-mean $M$ and the density gradient. In the portion of the $2 \mathrm{PC}$ experiment up to $4 \times \mathrm{CO}_{2}$ the correlation they found of $M$ with the density gradient is weak (the first seven triangles in their Fig. 3, beginning from the top), whereas the correlation with $-\mathbf{u}_{h} \cdot \nabla_{h} p$ is again 0.98 . We suggest that the higher correlation is likely to indicate a closer physical link. Thorpe et al. (2001) found that restricting the calculation of the meridional density gradient to the western boundary region gave a better correlation ( $R$. Thorpe, personal communication). This is probably because the majority of the flow in the AMOC occurs in this region, so the pressure gradient there, dependent on the density gradient, is most influential. Our use of $-\mathbf{u}_{h} \cdot \nabla_{h} p$ can be regarded as giving most weight to $\nabla_{h} p$ in just these regions, with $\mathbf{u}_{h}$ itself as the weighting factor. Thus $B$ is automatically focussed on the relevant regions.

In summary, the evidence presented in this section supports the hypothesis that work done by the pressure gradient in the Atlantic provides KE to the AMOC. In experiments with increasing $\mathrm{CO}_{2}$, the pressure gradient decreases, reducing the KE supply $B$, and the AMOC $M$ weakens in consequence. We have demonstrated a linear relationship between $M$ and $B$ in several CMIP3 AOGCMs.

\subsection{Spread in AOGCM simulations of AMOC weakening}

The decrease measured by $\sigma(M)$ in the AMOC strength during the $1 \%$ year ${ }^{-1} \mathrm{CO}_{2}$ experiment of a given model is the product of the reduction $\sigma(B)$ in KE input and the sensitivity $\mathrm{d} M / \mathrm{d} B$ of the circulation to the KE input. The former factor is related to the effect of climate change on the ocean density field, and the latter to the dynamics of the ocean, so it would be useful to know their relative importance in accounting for the model spread in $\sigma(M)$.

Table 2 gives the coefficient of variation (standard deviation divided by mean) for various quantities, excluding FAMOUS $(1 \mathrm{~h})$ because of its very close similarity to FAMOUS. Measured by this statistic, both $\sigma(B)$ and $\mathrm{d} M / \mathrm{d} B$ have a large model spread. There is a correlation of +0.55 across models between $\mathrm{d} M / \mathrm{d} B$ and $\sigma(M)$ (Fig. 11a), but the correlation of $\sigma(B)$ with $\sigma(M)$ is small (Fig. 11b). In these plots, especially the latter plot, ECHAM5/MPI-OM (marked E) and MIROC3.2 (hires) (marked I), are outliers.

There is no physical reason obvious to the authors for ECHAM5/MPI-OM to be an outlier, but it is notable that this model is the only one for which we obtain (a) $B<0$ in the Atlantic, (b) substantially different $\mathrm{d} M / \mathrm{d} B$ for computations from monthly and annual-mean data, (c) substantially different $B$ for the $1 \%$ year $^{-1} \mathrm{CO}_{2}$ and SRES A1B scenarios (the latter is discussed later). We think it is likely 

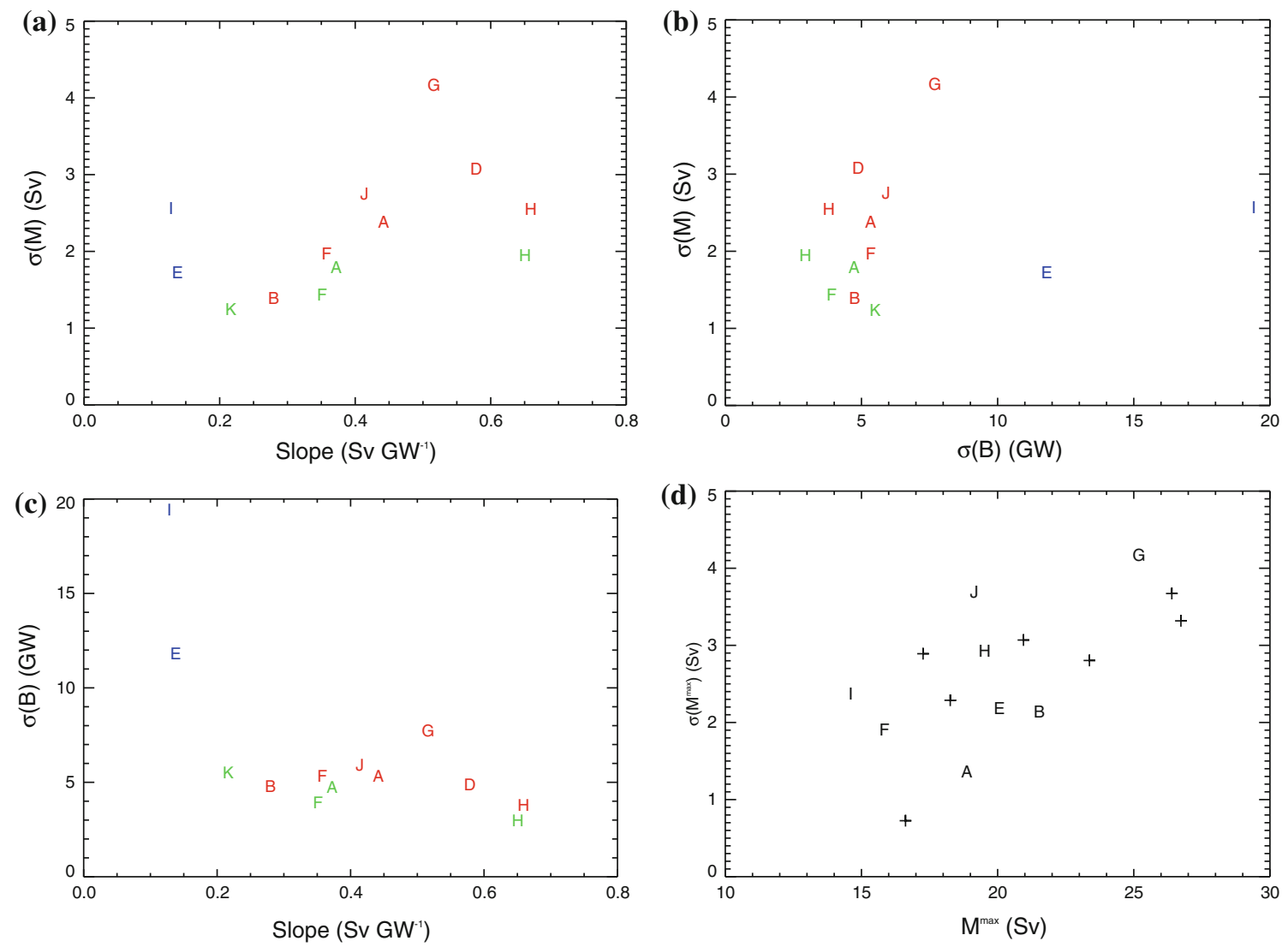

Fig. 11 Scatter plots of (a) change in AMOC strength at $45^{\circ} \mathrm{N} \sigma(M)$ (Sv) against $\mathrm{d} M / \mathrm{d} B\left(\mathrm{~Sv} \mathrm{GW}^{-1}\right)$, the sensitivity of $M$ to $\mathrm{KE}$ input in $50-70^{\circ} \mathrm{N}$ in the Atlantic; $(\mathbf{b}) \sigma(M)$ against $\sigma(B)(\mathrm{GW})$, the change in KE input; (c) $\sigma(B)$ against $\mathrm{d} M / \mathrm{d} B$; (d) change in maximum AMOC strength $\sigma\left(M^{\max }\right)(\mathrm{Sv})$ against its initial value $M^{\max }$. In all cases, $\sigma$ denotes the decadal standard deviation, which we use to measure the change during the integration. Letters identify the AOGCMs according to Table 2. In (a), (b) and (c), red and blue letters are for AOGCM

that there is an inaccuracy in our calculation of $-\mathbf{u}_{h} \cdot \nabla_{h} p$ due to some unidentified limitation in the CMIP3 diagnostics for this model.

In MIROC 3.2 (hires), $\mathrm{d} M / \mathrm{d} B$ is the smallest of all models, and $B$ and $\sigma(B)$ the largest by a factor of two. It is likely that the difference is related to this model's having a much higher ocean horizontal resolution than other CMIP3 ocean models $\left(0.28^{\circ}\right.$ latitude and $0.19^{\circ}$ longitude, the next highest being about $1^{\circ}$ ). Since it is the only eddy-permitting model, we suggest that within its eddying ocean there is much more local generation and dissipation of KE. We do not think that model resolution is generally the reason for the spread of $\sigma(B)$ and $\mathrm{d} M / \mathrm{d} B$. For example, at the opposite extreme to MIROC 3.2 (hires), MIROC 3.2 (medres) is the model with the smallest $\sigma(B)$ and largest $\mathrm{d} M / \mathrm{d} B$, but its ocean resolution of $1.4^{\circ}$ is not the lowest, while the two GFDL models have the same ocean resolution, but rather different $\sigma(B)$ and $\mathrm{d} M / \mathrm{d} B$.

integrations with $\mathrm{CO}_{2}$ increasing at $1 \%$ year $^{-1}$. The blue models (models $\mathrm{E}$ and $\mathrm{I}$ ) are not included in the correlations, as discussed in the text. Green letters are for integrations under scenario SRES A1B. In (d), both letters and symbols are for $1 \%$ year ${ }^{-1} \mathrm{CO}_{2}$ simulations; the symbols are for CMIP3 models not listed in Table 2, for which we could not successfully carry out the KE calculation. Model D is omitted in (d) because it has a strong control drift in $M^{\text {max }}$

If the two outlying models (E and I) are omitted, the remaining seven show correlations of +0.68 between $\sigma(B)$ and $\sigma(M)$ and +0.60 between $\mathrm{d} M / \mathrm{d} B$ and $\sigma(M)$, both significant at the $10 \%$ level (one-tailed). Both of them therefore contribute to the spread of AMOC projections.

To illustrate how this might work, we consider a conceptual model. Let $P$ be the pressure-gradient force driving the AMOC and $M$ its strength. Since $M$ is a measure of the velocity of the circulation, work is done on the AMOC by the pressure-gradient force at a rate $B=M P$, where the integration over volume and the constant of proportionality have been absorbed into $P$.

Generation $B$ of $\mathrm{KE}$ is balanced by dissipation $D$. During climate change, the diagnosis of the terms in the KE balance of HadCM3 and FAMOUS shows that $D$ and $B$ decrease together in the Atlantic i.e. $\Delta B=\Delta D$, and we presume the same holds for the other models, in which we do not have diagnostics to verify it explicitly. For the 
conceptual model, we postulate that $\Delta D=\gamma \Delta M$, where $\gamma$ is a model-dependent constant. Given that $M$ is only a single number characterising a complex 3D circulation, this can only be a rough approximation and we do not think that it is justifiable to assume a more complex functional form. Therefore $\Delta B=\gamma \Delta M$, which implies that $\Delta M \propto \Delta B$ during climate change in any given model, as demonstrated by Fig. 10 and the correlation coefficients of Table 2 , with the slope $\mathrm{d} M / \mathrm{d} B=1 / \gamma$ being a constant of that model. Thus the conceptual model also accounts for the correlations we find across AOGCMs between $\sigma(M)$ and $\sigma_{B}$ (which quantify $\Delta M$ and $\Delta B$ ) and between $\sigma_{M}$ and $\mathrm{d} M / \mathrm{d} B$ (Fig. 11a, b).

Climate change alters the density field, modifying $P$ by an amount $\Delta P$, so $\Delta B=M_{c} \Delta P+P_{c} \Delta M$, where the $c$ suffix denotes the control state. Our comparison of the correlations of $M$ with $B$ and $B_{p}$ above (Sect. 4.2) suggests that the first term is more important, so for the conceptual model we assume $\Delta B=M_{c} \Delta P$. Therefore the KE balance $\Delta B=$ $\Delta D$ requires thatl

$\Delta B=M_{c} \Delta P=\gamma \Delta M \Rightarrow \Delta M=\frac{M_{c}}{\gamma} \Delta P$,

a Stommel-type model-dependent relationship between changes in the circulation $\Delta M$ and in the driving force $\Delta P$. This conceptual model is the one we hypothesised earlier (end of Sect. 4), in which a decrease in the driving force $P$ reduces the supply of KE to the AMOC, leading to a weakening of the circulation in order to reduce the dissipation to match.

Since dissipation is controlled by $\gamma$, we would expect a model with greater viscosity to have larger $\gamma$ and smaller $\mathrm{d} M / \mathrm{d} B=1 / \gamma$, all else being equal. Consistent with this, $\mathrm{d} M / \mathrm{d} B$ is smaller in GFDL-CM2.0 than in GFDL-CM2.1, the higher viscosity in the former being one of the main differences between them (Gnanadesikan et al. 2006), and it is smaller in FAMOUS than in HadCM3, the viscosity being 50 times larger in FAMOUS.

If it is a model property, the same $\mathrm{d} M / \mathrm{d} B$ should be exhibited by a given model when forced by different scenarios. The CMIP3 database provides the relevant diagnostics to allow us to compute $B$ for only six AOGCMs under the SRES A1B scenario (Table 2; Fig. 10). In the five AOGCMs for which both A1B and $1 \%$ year ${ }^{-1} \mathrm{CO}_{2}$ are available, the $\Delta M-\Delta B$ relationships are similar for the two scenarios. There is an offset in the case of ECHAM5/MPIOM which we cannot explain, underlining our doubts about our results for this model (as mentioned above). The A1B integrations for the twenty-first century have somewhat smaller $\sigma(B)$ than the $1 \%$ year $^{-1}$ integrations to $4 \times \mathrm{CO}_{2}$, because the climate forcing is less; in terms of the conceptual model, $\Delta P$ and therefore $\Delta B=M_{c} \Delta P$ are smaller for A1B than for $4 \times \mathrm{CO}_{2}$ in a given AOGCM, but $\gamma$ is the same, so $\Delta M=\Delta B / \gamma$ is smaller. We show the A1B results, excluding models $\mathrm{E}$ and $\mathrm{I}$, in Fig. 11a-c. As far as this limited evidence goes, it suggests that our explanation of the spread of $\sigma(M)$ in the $1 \%$ year $^{-1}$ experiments in terms of the conceptual model applies to projections for the twenty-first century as well.

Although in the first instance the change in $B$ is the result of surface buoyancy forcing, which differs among models, the density field is also affected by turbulent mixing, and by changes in oceanic advection of temperature and salinity anomalies by the AMOC, which constitute feedbacks on AMOC change (Marotzke 1996; Thorpe et al. 2001; Swingedouw et al. 2007; Körper et al. 2009). Pardaens et al. (2010) show evidence in CMIP3 AOGCMs under the SRES A1B scenario for such relationships between AMOC change and density change in the Atlantic. A decrease in the AMOC is correlated with an increase in temperature and salinity in the subtropics, and a decrease in temperature and salinity at high latitudes, consistent with the reduction in northward advection of warm salty water, and opposing the influence of changes in surface fluxes of heat and freshwater. Negative advective feedback on AMOC changes will give an anticorrelation between $\mathrm{d} M /$ $\mathrm{d} B$ and $\sigma(B)$, because models in which the AMOC is very sensitive to KE input (large $\mathrm{d} M / \mathrm{d} B$ ) will tend to oppose change in $B$ (limiting $\sigma(B)$ ). Excluding the two outlying models, our present results do not give statistically significant evidence for an anticorrelation (Fig. 11c), but we have a limited set of AOGCMs, in particular not including GISS-ER or MRI-CGCM2.3.2, which gave the largest and smallest changes, respectively, in the AMOC of those considered by Pardaens et al. (2010).

In a different set of models, Gregory et al. (2005) noted a significant correlation between $M_{c}$ and $\sigma(M)$ i.e. models with a strong control AMOC strength tend to have a large decline under increasing $\mathrm{CO}_{2}$. In our smaller set of CMIP3 AOGCMs, there is also a correlation which is statistically significant but not robust-it depends on the inclusion of particular AOGCMs. However, the AMOC strength can also be calculated for six other CMIP3 AOGCMs in which we could not successfully carry out the KE analysis. Including these, to make an enlarged ensemble of 15 models, we obtain a correlation coefficient of 0.63 , which is significant at the 5\% level (one-tailed), between the maximum AMOC strength $M^{\max }{ }_{c}$, the quantity considered by Gregory et al. (2005), and $\sigma\left(M^{\max }\right)$, its decadal standard deviation during $\mathrm{CO}_{2}$ increase (Fig. 11d). (For $M_{c}$ and $\sigma(M)$ at $45^{\circ} \mathrm{N}$, we have 14 models available, and the correlation is 0.52 , which is also significant.) Our conceptual model could account for this correlation; Eq. 5 predicts that $\Delta M \propto M_{c}$ for given $\gamma$ and $\Delta P$. The physical reason for the relationship is that, if $M_{c}$ is large, the decrease in $\mathrm{KE}$ is also large when $P$ declines. 


\section{Discussion and conclusions}

AOGCMs predict a weakening of the AMOC during the twenty-first century in response to anthropogenic forcing of climate, but there is a large model uncertainty in the magnitude of the predicted change. In this work we have sought a quantitative explanation of the uncertainty by analysing the kinetic energy balance of the circulation. In experiments with $\mathrm{CO}_{2}$ increasing at $1 \%$ year ${ }^{-1}$, the largest change in the KE balance of the Atlantic in the HadCM3 and FAMOUS AOGCMs is a decrease in KE production $B$ by the pressure-gradient force in the north Atlantic, which correlates strongly in time with the declining strength $M$ of the AMOC, and is matched by a decrease in dissipation of KE.

The CMIP3 database does not include similar diagnostics of the KE balance, but we can estimate $B$ accurately enough for this purpose from other quantities, allowing us to demonstrate similar high correlations between $M$ and $B$ in seven other AOGCMs under the idealised $1 \%$ year $^{-1}$ $\mathrm{CO}_{2}$ scenario and scenario SRES A1B for the twenty-first century. The spread in their predictions of the decrease in the AMOC is due to model spread both in the change in $B$ as climate changes and in $\mathrm{d} M / \mathrm{d} B$, the sensitivity of the circulation to $\mathrm{KE}$ input. The change in $B$ relates to the pressure-gradient force, which is determined by the density field and affected by buoyancy fluxes; it is through $B$ that changes in high-latitude surface heat and freshwater fluxes can affect the AMOC. The slope $\mathrm{d} M / \mathrm{d} B$ relates to ocean dynamics, which determines the response of the AMOC to the forcing by changes in $B$; our hypothesis is that the circulation weakens so that dissipation reduces to match KE input. In models where $M$ is large in the unpertubed climate, the reduction in $B$ will also be large for a given change in the pressure gradient, and that will tend to produce a large reduction in $M$. Hence, the hypothesis could also account for the earlier observation by Gregory et al. (2005) that the weakening of the AMOC tends to be large in models having a strong control AMOC; we confirm that this correlation is found in CMIP3 AOGCMs as well.

Correlations between $M$ and the meridional pressure or density gradient have been shown before in AOGCMs. However, in a geostrophic ocean the connection between meridional forces and meridional circulation is not direct; the link is revealed more clearly by the analysis of the KE balance. Nevertheless the evidence we have presented is only "circumstantial". The generation of KE along the western boundary of the Atlantic and in the regions of deep water formation, the decline of $B$ particularly in the north Atlantic, and the correlations across models of the decline in $M$ with the decline in $B$ and with $\mathrm{d} M / \mathrm{d} B$ are all consistent with our hypothesis, but we still need a dynamical analysis of the circulation to understand the connection between $M$ and $B$. In particular we need a quantitative dynamical understanding of how the change in $B$ occurring particularly in high northern latitudes affects the AMOC at all latitudes. This involves a mechanism whereby changes in the meridional pressure gradient are converted to changes in the zonal pressure gradient, in order to accommodate the constraints of geostrophy (Griesel and Maqueda 2006). More generally, the mechanism is related to the adjustment of circulation and density to buoyancy forcing through wave propagation, as described e.g. by Kawase (1987), Hsieh and Bryan (1996) and Johnson and Marshall (2002).

We also need to relate KE production and dissipation to the $3 \mathrm{D}$ structure of the circulation. The unusual results in the present analysis from MIROC 3.2 (hires) suggest that analysis of other high-resolution eddy-resolving models might be revealing. Since the KE balance depends on the ageostrophic circulation, which is a very small fraction of the velocity, it may be difficult to relate model results to the real world, in which large-scale 3D circulation is usually inferred by assuming geostrophy in the interior (e.g. Cunningham et al. 2007). However a comparison with observations must be done if the reliability of AOGCMs is to be assessed and improved regarding the generation and dissipation of KE.

An advance made in this study is to offer a detailed view of the regional distribution of $B$ in ocean models, whereas previous studies concentrated on the global-mean sign of $B$. A global-mean $B<0$ has been interpreted as ruling out a buoyancy-driven AMOC. However, our analysis shows that conversion of both signs occur, with $B>0$ in the Atlantic. In that respect, the present study supports the buoyancy-driven view of the AMOC, which has been the subject of much debate recently (Tailleux 2009; Tailleux and Rouleau 2010). Apparently, the power required to maintain the AMOC is $<0.1 \mathrm{TW}$, which is a small fraction of the total mechanical energy input due to the wind and buoyancy forcing.

Under increased $\mathrm{CO}_{2}$, the changes in $B$ seem to contradict the pump/valve mechanism proposed by Samelson (2004), in which the southern winds control the strength of the AMOC by pumping APE into the system, which is then released by high-latitude cooling, an idea supported by the model experiments of Urakawa and Hasumi (2009). However, we find that the sink of KE in the Southern Ocean (converted to APE in this interpretation) increases as the climate changes, while the AMOC strength decreases. Some other studies agree that changes in windstress are not responsible for weakening the AMOC in time-dependent climate change (Dixon et al. 1999; Gregory et al. 2005). The contradiction could arise partly because transient $\mathrm{CO}_{2}$-forced changes occur on shorter timescales than those involved in establishing a steady- 
state balance. Delworth and Zeng (2008) show that the $\mathrm{AMOC}$ at $20^{\circ} \mathrm{N}$ in GFDL-CM2.1 strengthens by $2-3 \mathrm{~Sv}$ in response to intensified and poleward-shifted windstress over the Southern Ocean, as projected by the model for the twenty-second century under the A1B scenario, but this adjustment takes more than 100 years. Furthermore, it is small compared with the weakening of $8 \mathrm{~Sv}$ in the AMOC at $20^{\circ} \mathrm{N}$ that occurs in this model under the $1 \%$ year $^{-1} \mathrm{CO}_{2}$ scenario, although the radiative forcings are of similar magnitude (a little smaller in A1B).

We conclude that the KE budget is a useful tool in the analysis of model simulations and of the uncertainty in AMOC projections. Further progress requires more detailed study of particular models, and would be greatly assisted by the availability of accurate diagnostics of the KE budget in those models.

Acknowledgments The authors are grateful to their collaborators in the RAPID UK THCMIP project for many stimulating discussions, and to Oleg Saenko, Didier Swingedouw and two anonymous reviewers for their comments. This work was supported by grant NE/ C509366/1 of the RAPID programme of the UK Natural Environment Research Council. Jonathan Gregory's contribution was also supported by the National Centre for Atmospheric Science (Climate Programme) and the Joint Integrated Climate Programme, DECC/ Defra (GA01101), of the Department of Energy and Climate Change, and the Department for Environment, Food and Rural Affairs. We acknowledge the modelling groups for making their model output available as part of the World Climate Research Programme's CMIP3 multi-model dataset, the Program for Climate Model Diagnosis and Intercomparison (PCMDI) for collecting and archiving this data, and the WCRP's Working Group on Coupled Modelling (WGCM) for organizing the model data analysis activity. The WCRP CMIP3 multimodel dataset is supported by the Office of Science, US Department of Energy.

Open Access This article is distributed under the terms of the Creative Commons Attribution Noncommercial License which permits any noncommercial use, distribution, and reproduction in any medium, provided the original author(s) and source are credited.

\section{References}

Acheson DJ (1990) Elementary fluid dynamics. Oxford University Press, Oxford

Bingham RJ, Hughes CW (2009a) Geostrophic dynamics of meridional transport variability in the sub-olar North Atlantic. J Geophys Res 114:C12029. doi:10.1029/2009JC005492

Bingham RJ, Hughes CW (2009b) Signature of the Atlantic meridional overturning circulation in sea level along the east coast of North America. Geophys Res Lett 36:L02603. doi: 10.1029/2008GL036215

Cunningham SA, Kanzow T, Rayner D, Baringer MO, Johns WE, Marotzke J, Longworth HR, Grant EM, Hirschi JJM, Beal LM, Meinen CS, Bryden HL (2007) Temporal variability of the Atlantic meridional overturning circulation at $26.5^{\circ} \mathrm{N}$. Science 317:935-938. doi:10.1126/science.1141304

Delworth TL, Zeng F (2008) Simulated impact of altered Southern Hemisphere winds on the Atlantic meridional overturning circulation. Geophys Res Lett 35:L20708. doi:10.1029/ 2008GL035166

Dixon KW, Lanzante JR (1999) Global mean surface air temperature and North Atlantic overturning in a suite of coupled GCM climate change experiments. Geophys Res Lett 26:1885-1888

Dixon KW, Delworth TL, Spelman MJ, Stouffer RJ (1999) The influence of transient surface fluxes on North Atlantic overturning in a coupled GCM climate change experiment. Geophys Res Lett 26:2749-2752

Gent PR, McWilliams JC (1990) Isopycnal mixing in ocean circulation models. J Phys Oceanogr 20:150-155

Gent PR, Willebrand J, McDougall TJ, McWilliams JC (1995) Parameterizing eddy-induced tracer transports in ocean circulation models. J Phys Oceanogr 25:463-474

Gnanadesikan A, Slater RD, Swathi PS, Vallis GK (2005) The energetics of ocean heat transport. J Climate 18:2604-2616

Gnanadesikan A, Dixon KW, Griffies SM, Balaji V, Barreiro M, Beesley JA, Cooke WF, Delworth TL, Gerdes R, Harrison MJ, Held IM, Hurlin WJ, Lee HC, Liang Z, Nong G, Pacanowski RC, Rosati A, Russell J, Samuels BL, Song Q, Spelman MJ, Stouffer RJ, Sweeney CO, Vecchi G, Winton M, Wittenberg AT, Zeng F, Zhang R, Dunne JP (2006) GFDL's CM2 global coupled climate models. Part ii: The baseline ocean simulation. J Climate 19:675-697

Gordon C, Cooper C, Senior CA, Banks H, Gregory JM, Johns TC, Mitchell JFB, Wood RA (2000) The simulation of SST, sea ice extents and ocean heat transports in a version of the Hadley Centre coupled model without flux adjustments. Clim Dyn 16:147-168

Gregory JM (2000) Vertical heat transports in the ocean and their effect on time-dependent climate change. Clim Dyn 16:501-515

Gregory JM, Church JA, Boer GJ, Dixon KW, Flato GM, Jackett DR, Lowe JA, O'Farrell SP, Roeckner E, Russell GL, Stouffer RJ, Winton M (2001) Comparison of results from several AOGCMs for global and regional sea-level change 1900-2100. Clim Dyn $18: 225-240$

Gregory JM, Dixon KW, Stouffer RJ, Weaver AJ, Driesschaert E, Eby M, Fichefet T, Hasumi H, Hu A, Jungclaus JH, Kamenkovich V, Levermann A, Montoya M, Murakami S, Nawrath S, Oka A, Sokolov AP, Thorpe RB (2005) A model intercomparison of changes in the Atlantic thermohaline circulation in response to increasing atmospheric $\mathrm{CO}_{2}$ concentration. Geophys Res Lett 32:L12703. doi:10.1029/2005GL023209

Griesel A, Maqueda MAM (2006) The relation of meridional pressure gradients to North Atlantic deep water volume transport in an ocean general circulation model. Clim Dyn 26:781-799. doi: 10.1007/s00382-006-0122-z9

Hsieh WW, Bryan K (1996) Redistribution of sea level rise associated with enhanced greenhouse warming: a simple model study. Clim Dyn. 12:535-544

Huang RX, Wang W, Liu LL (2006) Decadal variability of windenergy input to the world ocean. Deep Sea Res II 53:31-41. doi: 10.1016/j.dsr2.2005.11.001

Hughes GO, Hogg AM, Griffiths RW (2009) Available potential energy and irreversible mixing in the meridional overturning circulation. J Phys Oceanogr 39:3130-3146. doi:10.1175/2009 JPO4162.1

Hughes TMC, Weaver AJ (1994) Multiple equilibria of an asymmetric two-basin ocean model. J Phys Oceanogr 24:619-637

Johnson HL, Marshall DP (2002) A theory for surface Atlantic response to thermohaline variability. J Phys Oceanogr 32:11211132

Jones CD, Gregory JM, Thorpe RB, Cox PM, Murphy JM, Sexton DMH, Valdes P (2005) Systematic optimisation and climate simulation of FAMOUS, a fast version of HadCM3. Clim Dyn 25:189-204. doi:10.1007/s00382-005-0027-2 
Kawase M (1987) Establishment of deep ocean circulation driven by deep-water production. J Phys Oceanogr 17:2294-2317

Kleinen T, Osborn TJ, Briffa KR (2009) Sensitivity of climate response to variations in freshwater hosing location. Ocean Dynamics 59:509-521. doi:10.1007/s10236-009-0189-2

Körper J, Spangehl T, Cubasch U, Huebener H (2009) Decomposition of projected regional sea level rise in the North Atlantic and its relation to the AMOC. Geophys Res Lett 36:L19714. doi: 10.1029/2009GL039757

Kuhlbrodt T, Rahmstorf S, Zickfeld K, Vikebo FB, Sundby S, Hofmann M, Link PM, Bondeau A, Cramer W, Jaeger C (2009) An integrated assessment of changes in the thermohaline circulation. Clim change 96:489-537. doi:10.1007/s10584-009-9561-y

Levermann A, Mignot J, Nawrath S, Rahmstorf S (2007) The role of northern sea ice cover for the weakening of the thermohaline circulation under global warming. J Climate 20:4160-4171. doi: $10.1175 / \mathrm{JCLI} 4232.1$

Lowe JA, Gregory JM (2006) Understanding projections of sea level rise in a Hadley Centre coupled climate model. J Geophys Res 111:C11014. doi:10.1029/2005JC003421

Marotzke J (1996) Analysis of thermohaline feedbacks. In: Anderson DLT, Willebrand J (eds) Dynamics and Predictability. Decadal climate variability. Springer, Berlin

Meehl GA, Stocker TF, Collins WD, Friedlingstein P, Gaye AT, Gregory JM, Kitoh A, Knutti R, Murphy JM, Noda A, Raper SCB, Watterson IG, Weaver AJ, Zhao Z (2007) Global climate projections. In: Solomon S, Qin D, Manning M, Chen Z, Marquis M, Averyt KB, Tignor M, Miller HL (eds) Climate change 2007: The physical science basis. Contribution of Working Group I to the Fourth Assessment Report of the Intergovernmental Panel on Climate Change. Cambridge University Press, Cambridge

Munk W, Wunsch C (1998) Abyssal recipes II: energetics of tidal and wind mixing. Deep Sea Res I 45:1977-2010

Nakićenović N, Alcamo J, Davis G, de Vries B, Fenhann J, Gaffin S, Gregory K, Grübler A, Jung TY, Kram T, La Rovere EL, Michaelis L, Mori S, Morita T, Pepper W, Pitcher H, Price L, Riahi K, Roehrl A, Rogner HH, Sankovski A, Schlesinger M, Shukla P, Smith S, Swart R, van Rooijen S, Nadejda V, Dadi Z (2000) Emission scenarios. A special report of Working Group III of the Intergovernmental Panel on Climate Change. Cambridge University Press, Cambridge, $599 \mathrm{pp}$

Oort AH, Ascher SC, Levitus S, Peixoto JP (1989) New estimates of the available potential energy in the world ocean. J Geophys Res 94:3187-3200

Pardaens AK, Gregory JM, Lowe JA (2010) A model study of factors influencing projected changes in regional sea level over the $21 \mathrm{st}$ century. Clim Dyn. doi:10.1007/s00382-009-0738-x

Petoukhov V, Ganopolski A, Brovkin V, Claussen M, Eliseev A, Kubatzki C (2000) CLIMBER-2: A climate model of intermediate complexity. Part I: model description and performance for present climate. Clim Dyn 16:1-17

Rahmstorf S (1996) On the freshwater forcing and transport of the Atlantic thermohaline circulation. Clim Dyn 12:799-811

Saenko OA, Eby M, Weaver AJ (2004) The effect of sea-ice extent in the North Atlantic on the stability of the thermohaline circulation in global warming experiments. Clim Dyn 22:689-699. doi: 10.1007/s00382-004-0414-0

Saenko OA, Fyfe JC, England MH (2005) On the response of the oceanic wind-driven circulation to atmospheric $\mathrm{CO}_{2}$ increase. Clim Dyn 25:415-426. doi:10.1007/s00382-005-0032-5

Saenko OA, Weaver AJ, Robitaille DY, Flato GM (2007) Warming of the subpolar Atlantic triggered by freshwater discharge at the continental boundary. Geophys Res Lett 34:L15604. doi: 10.1029/2007GL030674
Samelson RM (2004) Simple mechanistic models of middepth meridional overturning. J Phys Oceanogr 34:2096-2103

Schmittner A, Latif M, Schneider B (2005) Model projections of the North Atlantic thermohaline circulation for the 21st century assessed by observations. Geophys Res Lett 32:L23710. doi: 10.1029/2005GL024368

Scott RB, Xu Y (2009) An update on the wind power input to the surface geostrophic flow of the world ocean. Deep Sea Res I 56:295-304. doi:10.1016/j.dsr.2008.09.010

Smith RS, Gregory JM (2009) A study of the sensitivity of ocean overturning circulation and climate to freshwater input in different regions of the North Atlantic. Geophys Res Lett 36:L15701. doi:10.1029/2009GL038607

Smith RS, Osprey A, Gregory JM (2008) A description of the FAMOUS (version XDBUA) climate model and control run. Geosci Model Devel 1:53-68

Spence P, Saenko OA, Eby M, Weaver AJ (2009) The southern ocean overturning: parameterized versus permitted eddies. J Phys Oceanogr 39. doi:10.1175/2009JPO4120.1

Stocker TF, Wright DG, Mysak LA (1992) A zonally averaged, coupled ocean-atmosphere model for paleoclimate studies. J Climate 5:773-797

Stommel HM (1961) Thermohaline convection with two stable regimes of flow. Tellus A 13:224-230

von Storch JS, Sasaki H, Marotzke J (2007) Wind-generated power input to the deep ocean: An estimate using a 1/10-degrees general circulation model. J Phys Oceanogr 37:657-672. doi: 10.1175/JPO3001.1

Stouffer RJ, Yin J, Gregory JM, Dixon KW, Spelman MJ, Hurlin W, Weaver AJ, Eby M, Flato GM, Hasumi H, Hu A, Jungclaus J, Kamenkovich IV, Levermann A, Montoya M, Murakami S, Nawrath S, Oka A, Peltier WR, Robitaille DY, Sokolov A, Vettoretti G, Weber N (2006) Investigating the causes of the response of the thermohaline circulation to past and future climate changes. J Climate 19:1365-1387

Swingedouw D, Braconnot P, Delecluse P, Guilyardi E, Marti O (2007) Quantifying the AMOC feedbacks during a $2 \times \mathrm{CO}_{2}$ stabilization experiment with land-ice melting. Clim Dyn 29:521-534. doi:10.1007/s00382-007-0250-0

Tailleux R (2009) On the energetics of stratified turbulent mixing, irreversible thermodynamics, Boussinesq models and the ocean heat engine controversy. J Fluid Mech 638:339-382. doi: 10.1017/S002211200999111X

Tailleux R, Rouleau L (2010) The effect of mechanical stirring on horizontal convection. Tellus A 62A:138-153

Thorpe RB, Gregory JM, Johns TC, Wood RA, Mitchell JFB (2001) Mechanisms determining the Atlantic thermohaline circulation response to greenhouse gas forcing in a non-flux-adjusted coupled climate model. J Climate 14:3102-3116

Toggweiler JR, Samuels B (1998) On the ocean's large-scale circulation near the limit of no vertical mixing. J Phys Oceanogr 28:1832-1852

Urakawa LS, Hasumi H (2009) The energetics of global thermohaline circulation and its wind enhancement. J Phys Oceanogr 39:1715-1728. doi: $10.1175 / 2009 J P O 4073.10$

Vellinga M, Wood RA (2002) Global climatic impacts of a collapse of the Atlantic thermohaline circulation. Clim Change 54:251267

Vellinga M, Wood RA (2007) Impacts of thermohaline circulation shutdown in the twenty-first century. Clim Change. doi: 10.1007/s10584-006-9146-y

Weaver AJ, Sarachik ES (1990) On the importance of vertical resolution in certain ocean general circulation models. J Phys Oceanogr 20:600-609 
Weaver AJ, Eby M, Kienast M, Saenko OA (2007) Response of the Atlantic meridional overturning circulation to increasing atmospheric $\mathrm{CO}_{2}$ : Sensitivity to mean climate state. Geophys Res Lett 34:L05708. doi:10.1029/2006GL028756

Wolfe CL, Cessi P, McClean JL, Maltrud ME (2008) Vertical heat transport in eddying ocean models. Geophys Res Lett 35:L23605. doi:10.1029/2008GL036138
Wright DG, Stocker TF (1991) A zonally averaged ocean model for the thermohaline circulation. Part I: The model development and flow dynamics. J Phys Oceanogr 21:1713-1724

Wunsch C (1998) The work done by the wind on the oceanic general circulation. J Phys Oceanogr 28:2332-2340 